PANORÁMICA SOBRE OTROS SISTEMAS CONSTITUGIONALES 


\title{
NOTAS SOBRE LA CIENCIA DEL DERECHO EUROPEO (CONTEXTO, DEBATES Y PERSPECTIVAS DE DESARROLLO DE LA TEORÍA GENERAL DEL DERECHO DE LA UNIÓN EUROPEA DESDE EL PUNTO DE VISTA ALEMÁN)*
}

\author{
ARMIN VON BOGDANDY \\ Catedrático de Derecho Comunitario \\ Frankfurt am Main
}

\section{CONTEXTO DE LOS DEBATES}

\section{LAS RAZONES DE SU COMPLEJIDAD}

Este trabajo, por deseo de los organizadores, debe dar cuenta del "estado de cosas y perspectivas de desarrollo de los conceptos jurídicos en el proceso europeo de integración". Tal deseo es imposible de satisfacer; las razones conforman una buena introducción al tema.

Sin duda, el volumen de producción científica impide cualquier visión general o síntesis. A comienzos de los noventa, las nuevas publicaciones de temática europea ocupaban cada mes dos metros de biblioteca en el Instituto de Derecho Internacional y Derecho Comparado de la Universidad Libre de

* Esta edición es una versión ampliada de la conferencia dictada por el autor en la reunión organizada por el Arbeitskreis Europäische Integration, reunión que llevaba como tema "Estado y desarrollo de los conceptos teóricos relativos al proceso de integración europea".

Traducción de Miguel AzPITARTE SÁNCHez (Becario de investigación de la Universidad de Granada). Revisada por Armin von Bogdandy. 
Berlín ${ }^{1}$. El número de publicaciones, en atención a la ampliación de la Unión Europea y a la profundidad de la integración, debería crecer masivamente en ámbitos esenciales como política interior, política jurídica o política exterior. A todo esto hemos de añadir las publicaciones periódicas. La biblioteca del Instituto Max-Planck de Heidelberg para Derecho público extranjero y Derecho internacional cuenta con más de cuarenta revistas, que de acuerdo con sus títulos se incardinarían en la temática europea. Además, prácticamente toda revista jurídica contiene ocasionalmente trabajos de Derecho comunitario, lo que muestra los profundos efectos de la integración jurídica; a menudo, este tipo de contribuciones dominan ediciones especiales. E incluso, llegados a este punto, el comunitarista cuidadoso no debe permanecer tranquilo: también los economistas y los politólogos se ocupan del Derecho comunitario, incorporando importantes resultados ${ }^{2}$.

Sin embargo, las dificultades para realizar una síntesis no resultan exclusivamente de la cantidad de producción científica, sino también de su forma. Sólo algunos trabajos ordenan un planteamiento teórico en el sentido de un método específico y extensivo o un boceto conceptual del objeto de investigación, de modo que la teoría pueda realizar su singular tarea de reducción de la compleji$\mathrm{dad}^{3}$. La causa no es únicamente que, como señaló U. Everling en un coloquio, los ejercientes de la práctica jurídica hayan dado forma de disciplina autónoma al Derecho comunitario. La razón es más profunda y general: se trata de la función primaria de la ciencia jurídica como ciencia práctica, que consiste en el "cuidado" de una importante "infraestructura" social ${ }^{4}$, principalmente en la producción y garantía de la transparencia y coherencia del Derecho ${ }^{5}$. En cuanto que la concreción teórica genera enfrentamientos, la abstinencia teórica debería ser de gran ayuda en una inicial tarea práctica: en la solución de problemas prácticos es más fácil lograr el consenso que en la proposición de proyectos teóricos ${ }^{6}$. De modo

1. Después no me ha sido posible trabajar con una biblioteca que adquiriera bibliografía en tales dimensiones.

2. Así los politólogos se ocupan de las instituciones, la legitimidad, los procesos y el concepto de Derecho, los economistas investigan, sobre todo, la función económica del Derecho, para mayor concreción véanse los epígrafes II 2 y 4 . En la política de investigación la interdisciplinariedad está de moda, comparar como ejemplo la política de desarrollo de la DFG sobre el tema "Gobernar en la Unión Europea" bajo la dirección de Beate Kohler-Koch. En sentido programático F. SNYDER: "New Directions in European Community Law", Journal of Law and Society 14 (1987), p. 167.

3. El debate en la ciencia política parece ordenado, M. JACHTENFUCHS/B. KOHLER-KOCH: «Einleitung: Regieren im dynamischen Mehrebenensystem", en Europäische Integration, Ed. por los autores citados, 1996 , p. 15

4. Por ello algunos autores reconocer a la ciencia jurídica como parte del sistema jurídico y no como parte del sistema científico, N. LuHMANn: Das Recht der Gesellschaft, 1993, pp. 274 y ss.

5. Debido a este motivo el Derecho comunitario continental no puede elaborar fácilmente una ciencia del Derecho comunitaria adecuada para el modelo británico. La ciencia jurídica inglesa, en atención a la fuerte significación de la práctica jurídica, está en una situación diferente a la continental, P.S. ATYYAн/R.S. Summer: Form and Substance in Anglo-American Law, 1991, pp. 403 y ss.; M. Loughun: Public Law and Political Theory, 1992, pp. 138 y ss.

6. Con esta opinión comenzó la integración euroepa, R. ScHuman: «Erklärung über eine Montanunion vom 9. Mai 1950", en 45 Jahre Ringen um die Europäische Verfassung: Dokumente 1939-1984, Ed. W. Lipgens, 1986, p. 293. 
similar se conforma la formación del jurista académico ${ }^{7}$. Si se observan de cerca los mecanismos mediante los cuales se satisfacen las tareas de la ciencia jurídica, salta a la vista un fenómeno significativo: la unidad del método (de modo más moderado: la universal aceptación de un modelo de argumentación) en la ciencia jurídica, que, en oposición a otras ciencias, permite una discusión inmediata y provoca resultados científicos con aplicación práctica directa. Sin embargo, faltan criterios ordenadores, que en otras ciencias posibilitan la clasificación de la producción.

En los trabajos de Derecho comunitario fracasa mayoritariamente el esquema clasificador "Derecha-Izquierda", que en no pocas ocasiones se utiliza a nivel nacional para categorizar los trabajos. En casi todas las posiciones de principio del Derecho comunitario aparecen representantes de los dos grandes espacios políticos. La antigua oposición ha perdido su función ordenadora respecto a las preguntas capitales de futuro ${ }^{8}$. Una cierta función sustitutiva ha cumplido la hasta ahora resonante división entre europeístas y euroescépticos. Sin embargo, para una sistematización jurídico-científica tiene una importancia menor, por cuanto que sus fundamentos son demasiado inseguros. Hoy -después de una amplia realización del mercado interior y la unión monetaria- es incierto y en alto grado discutido cuál debe ser el objeto de una ulterior integración: la simplista solución "más competencias centrales", "más Derecho comunitario", "más entrelazamientos sociales" como denominador común de casi todas las concepciones ya no moviliza. Las posiciones iniciales, que en atención a la embrionaria situación de la Comunidad defendieron como principio jurídico autónomo la integración ${ }^{9}$, se ven sometidas a solidas críticas y cada vez reciben menos apoyos ${ }^{10}$.

Para abarcar la exposición del tema "estado de cosas y perspectivas de desarrollo de los conceptos jurídicos en el proceso europeo de integración", ¿es necesario trabajar sobre la inmensa cantidad bibliográfica, o se puede uno limitar a la producción -esencialmente poca- que reclama una concepción específica, cuyo proyecto se elabora en torno a la teoría general? Respecto a las relaciones entre la producción jurídica del día a día y las contribuciones especificas al debate de fondo se pueden formular dos hipótesis enfrentadas. Una dispone que los trabajos orientados a la práctica, parten de proposiciones de principio, que en última instancia desarrollan las "grandes" concepciones y que, por ello, no son interesantes

7. Propuesta que encuentra poca comprensión por parte de M. SHAPIRO: «it represents a stage of constitutional scholarship out of which American constitutional law must have passed about seventy years ago [...]. Such an approach has proved fundamentally arid in the study of individual constitutions", "Comparative Law and Comparative Politcs", Soutbern California Law Rewiev, 53 (1980), pp. $537,538$.

8. No se ha de excluir que se desfiguren las tradicionales lineas de conflicto en las discusiones sobre política jurídica, política interior, política exterior y política fiscal.

9. H. KuTsCher: "Thesen zu den Methoden der Auslegung des Gemeinschaftsrechts aus der Sicht eines Richters", en Begegnung von Justiz und Hochscbule 27.-28. September 1976, Ed. Tribunal de Justicia, pp. I-41; también F. MAncini/D. KeELING: "Democracy and the European Court of Justice", MLR 57 (1994), pp. 175, 186.

10. Respecto a las críticas J. ISENSEE: “Integrationsziel Europastaat?», en FS Everling, 1995, pp. 567, 570; R. VAUBEL: "The Centralisation of Western Europe. The Common Market, Political Integration, and Democracy", Hobart Paper 127, Institute of Economic Affairs, London, 1995. 
en este contexto. Más enriquecedora me parece la hipótesis opuesta: algunos de estos trabajos, en atención a su conexión con la realidad, pueden desprender nuevas concepciones del proceso integrador, cuyo desarrollo todavía esta pendiente $^{11}$.

\section{MECANISMOS DE SELECCIÓN}

En atención al volumen y complejidad de la producción científica se hacen necesarios mecanismos de selección. Un primer mecanismo habitual consiste en limitarse a la específica producción jurídica. Las reflexiones de otras disciplinas serán asumidas sólo por algunos sectores de la ciencia jurídica ${ }^{12}$. La mayoría de los autores alemanes, en la tradición de la ciencia jurídica como disciplina autónoma, trabajan exclusivamente sobre bibliografía jurídica ${ }^{13}$.

Ciertamente, un proceso interdisciplinar engendra peligros cuando no se atiende cuidadosamente a los distintos contextos de desarrollo y aplicación ${ }^{14}$. La construcción jurídico científica impone en primer lugar una penetración en el Derecho válido con la finalidad de despejar en una perspectiva proponente los principios fundamentales y las estructuras ordenadoras ${ }^{15}$. Otro es, por contra, el interés de la sociología: pretende la identificación de las fuerzas sociales determinantes en la integración con la intención de alcanzar pronósticos sobre el futuro desarrollo causal en virtud de enunciados generales ${ }^{16}$. También falta una teoría que medie entre los resultados de la ciencia jurídica y de la sociología ${ }^{17}$. Por otro lado, la Teoría del Derecho, ha descubierto numerosos puntos de partida $^{18}$ de leges artis, que permiten una utilización metodológicamente controlada de los resultados de otras ciencias. Un número de significativos

11. En este sentido, G.W.F. Hegel: Grundlinien der Philosophie des Rechts, 1821 (1970), p. 21. Respecto al sentido de los llamados ámbitos de referencia para la teoría general, E. SCHMIDT-AßMANN: Das allgemeine Verwaltungsrecht als Ordnungsidee, 1998, pp. 8 y ss.

12. Especialmente receptivo es el nuevo Derecho comunitario británico, cfr. las contribuciones en New Legal Dynamics of European Union, Ed. J. Shaw/G. Moore, 1995. El Derecho comunitario en lengua alemana cuenta con el Arbeitskreis Europäische Integration, foro interdisciplinar escasamente aprovechado.

13. La tradicional comprensión formulada de manera poco ortodoxa, LuHMANN, Metamorphosen des Staates", Information Philosophie 4/1994 (nota 12), pp. 38 y ss.

14. Así el análisis politológico sobre interdependencias apenas es aplicable en cuanto que no atiende a los aspectos de formación de la voluntad que incorporan los distintos procesos, F. SCHARPF: Regieren in Europa. Effektiv und demokratisch?, 1999, pp. 27 y ss.

15. U. NEUMANN: "Wissenschaftstheorie und Rechtswissenschaft", en Einführung in die Rechtsphilosophie und Rechtstheorie der Gegenwart. 6." Ed., Kauffmann/Hassemer, 1994, pp. 422 y 434.

16. R. MEYERS: «Metatheoretische und methodologische Betrachtungen zur Theorie der internationalen Beziehungen", en Theorien der internationalen Beziehungen, Ed. Rittberger, PSV Sonderheft 21/1990, pp. 48, 49, 53 y ss.

17. Acercándose a esta mediación C. JOERGES: «Das Recht im Prozess der europäischen Integration”, en Jachtenfuchs/Kohler-Koch (nota 3), p. 73; M. JACHTENFUCHS: "Theoretical perspectives on European Governance", ELJ 1 (1995), p. 115.

18. R. ALEXY: Theorie der juristischen Argumentation, 2." Ed., 1991, pp. 261 y ss. 
trabajos muestra lo fructífero del encuentro entre los conocimientos de la sociología y de la ciencia jurídica ${ }^{19}$.

Otro mecanismo de selección, aún más extendido en la práctica europea, supone concentrarse en las publicaciones escritas en la lengua propia del sistema jurídico del autor ${ }^{20}$. Ello se corresponde con la ordenación institucional de la ciencia jurídica y con el modelo de carrera académica dominante. No conozco -con excepción de las condiciones materiales y de admisión que constituyen la responsabilidad nacional por incumplimiento del Derecho comunitario- ninguna posición francófona ${ }^{21}$, española o italiana que haya recibido un amplio eco en el ámbito de lengua alemana ${ }^{22}$.

Con el tiempo parece que las relaciones entre los comunitaristas de distintos países han disminuido en vez de aumentar. Llamativo es el fracaso de la Fédération Internationale de Droit Européen. En sí, la cuota de participación en sus jornadas asegura la exclusividad; la mayoría de los participantes han dicho pocas cosas buenas de su organización y de su cultura de discusión. A mí no me fue posible encontrar recopiladas las distintas ponencias; evidentemente todavía no se han editado. Una recepción -comparable con los trabajos de la Asociación alemana de profesores de Derecho del Estado- no encuentra lugar. Sólo están a disposición las ponencias alemanas ${ }^{23}$. Esta asociación no ha sido capaz de transformar la malla formada de modo personal por los primeros comunitaristas en una significativa estructura organizativa que conduzca a la integración de la actual Ciencia del Derecho comunitario. Igualmente, el contacto entre las redacciones de las distintas revistas de Derecho comunitario, fundada por Claus-Dieter Ehlermann durante su trabajo en el servicio jurídico de la Comisión, no ha sido continuado por su sucesor.

Entre los debates, esencialmente nacionales, existen algunas conexiones ${ }^{24}$. Las más importantes son contribuciones de prominentes personajes, cuya llamativa función como protagonistas del sistema jurídico y autores científicos refleja la naturaleza propia de la publicaciones jurídicas. En primer lugar se hallan los autores cuya preeminencia reside en su pertenencia al Tribunal de Justicia, sin duda Ulrich Everling o Manfred Zuleeg, Walter van Gerven, Gil Carlos Rodríguez Iglesias, Robert Lecourt, Koenraad Lenaerts, Guiseppe Federico Mancini, Pierre Pescatore o Pieter VerLoren van Themaat, Deirdre Curtin, Claus-Dieter Ehlermann, Paul Kirchhof,

19. Cfr. H.P. IPSEN: Europäisches Gemeinschaftsrecht, 1972; J.H. Weiler: Il sistema comunitario europeo, 1985.

20. Una excepción significativa se encuentra en numerosas contribuciones de los Países Bajos.

21. El tándem político franco-alemán, por muchos visto como el motor de la integración (P. DF SCHOUTHEETE: "The European Community and its sub-systems", en The Dynamics of European Integration, Ed. Wallace, 1991, pp. 106, 108 y ss.) no ha tenido una correspondencia científica. En cuanto a la recepción vid. C.D CLASSEN: "Die deutsche Europarechtswissenschaft und Frankreich: die Geschichte einer punktuellen Wahrnehmung”, en Eine deutsch-französische Rechtswissenschaft?, Ed. Beaud/Heyen, 1999, p. 351.

22. Para la importancia de las posiciones inglesas atiéndase al posterior epígrafe III.

23. Cfr. R. v. BORRIES: "Das Subsidiaritätsprinzip im Recht der Europäischen Union", EuR 1994, p. 263; 17 FIDE-Kongress vom 9.-12. Oktober in Berlin. Die deutschen Landesbericbte. EuR Beiheft 1/1997, Ed. J. Schwarze/P.-C. Müller-Graff. grafe III

24. Respecto a la Common Market Law Review y al Europäisches Hochschulinstitut ver el epí- 
Henry G. Schermers y Joseph $\mathrm{H}$. Weiler serían los pocos que sin haber sido jueces del Tribunal de Justicia pertenecen a este prominente círculo ${ }^{25}$. Sin embargo, estos autores, en pocas ocasiones se plantean en sus contribuciones sintetizar el estado del debate.

En vista de esta situación, la siguiente exposición únicamente puede ofrecer mi ordenación subjetiva, que por razones de espacio ha de dejar a un lado algunos planteamientos valiosos ${ }^{26}$. De los múltiples debates sólo se referirán aquellos imputables a la teoría general del Derecho comunitario ${ }^{27}$.

\section{POSICIONES Y DEBATES}

\section{ESTADO y CONSTITUCIÓN}

La Unión no es un Estado, así lo entiende la doctrina dominante en la academia $^{28}$. Sin embargo, el Estado representa de una manera más o menos abierta un punto de referencia central en todas las ulteriores reflexiones. ¿Cómo podría ser de otro modo? Hasta ahora el Estado había sido la única forma de dominio político y jurídico. Todo el conjunto de instituciones y conceptos propios del dominio político encontraban en el Estado su punto de partida.

Incluso sería fácil proyectar al Estado como metadiscurso de los debates singulares. Muchos debates podrían presentarse a lo largo de un antagonismo claro y simple, posiciones de "Derecho del Estado" versus posiciones de "Derecho comunitario" ${ }^{29}$, que se funda en la decisión sobre un sola pregunta: ¿tiene la dominación política su espacio adecuado en una comunidad compuesta como Estado-nación o son imaginables formas de organización no estatales y realizables en la Unión? Dicho de otro modo: ¿se ha de preservar la unidad jurídica y política realizada en el Estado ${ }^{30}$ tanto como sea posible, u ofrece la Unión Europea una nueva alternativa histórica que se ha de aprovechar y que permite elaborar una novedosa forma de dominio político y jurídico con su propia lógica? Numerosas posiciones, con-

25. En ámbitos concretos hay más autores que aparecen como referentes a nivel europeo, por ejemplo Jean-Victor Louis para la unión monetaria.

26. Una compilación de los debates en lengua inglesa la ofrecen las variadas contribuciones al libro de P. Craig/G. De BurCa: The Evolution of EU Law, 1999.

27. No se expondrán debates importantes como los referidos a la eficacia directa de las Directivas, al ámbito de aplicación, dogmática y eficacia entre particulares de las libertades comunitarias, la extensión de las diversas cláusulas de igualdad o las complejidades de la distribución competencial.

28. La posiciones en contra están aisladas y no han podido trasformarse en un profundo proyecto de investigación, D. DicKE: Das Verbältnis der Schweiz zum real existierenden Westeuropäischen Bundesstaat, 1991; R. ScHOLZ: “Grundgesetz und europäische Einigung", NJW, 1992, pp. 2593 y 2594; en detalle H. GRAms: Zur Gesetzgebung der Europäischen Union, 1998, pp. 225 y ss.; cfr. también G. MajONE: "The European Community as a Regulatory State", en Collected Courses of the Academy of European Law 1994-Vol. V-1, Ed. Academy of European Law, 1996, p. 321.

29. R. STREINZ: Bundesverfassungsgerichtlicher Grundrechtsschutz und Europäisches Gemeinschaftsrecht, 1989, pp. 88 y ss.

30. Sobre los vericuetos de la unidad U. HALTERN: “Europäischer Kulturkampf", Der Staat 37 (1998), pp. 591, 594 y ss. 
cernientes a la forma de la Unión (como unión de Estados-nación o como comunidad singular), a la medida de su dependencia de la legitimidad nacional-estatal, a su organización, a la (falta de) autonomía de su Derecho o al (ausente) carácter constitucional de su Derecho primario, pueden ordenarse desde el trasfondo de este dualismo. Sin embargo, el presente artículo no se adentrará en este camino, pues la complejidad que tal debate ha ganado en los diez últimos años no permite hacerlo en su justa medida.

Sin embargo, casi ningún camino marcha al margen de los institutos jurídicos acuñados por el Derecho del Estado. El llamamiento programático de Josephine Shaw y Antje Wiener para dejar a un lado del Derecho comunitario ${ }^{31}$ el "touch of stateness $^{32}$, me parece poco fértil pues habría de asumir las implicaciones que supone realizar una tábula rasa conceptual. El pensamiento jurídico es en su esencia comparativo y necesita de elementos de la tradición dogmática, que toman cuerpo en instituciones útiles para la vida. El impulso no estatalista debe consistir mucho más en disolver la impregnación estatal de los institutos jurídicos que versan sobre la constitución, la dirección y el control del poder, para avanzar en el contenido de modernidad europea en ellos acuñados con la vista puesta en la Unión y en la forma de dominio político y jurídico que incorpora. La opinión de que la Unión no es un Estado y nunca lo será es un mero pretexto de reconstrucción que, sin embargo, apenas pretende contenidos y direcciones. La concreción de la forma "sui-generis" de la Unión dependerá todavía durante un largo trecho del desarrollo de los conceptos de Derecho público ya establecidos. A menudo, la fórmula "sui-generis" es sólo una careta que enmascara impotencia clasificatoria, y no un motivo para reflexionar genéricamente sobre cómo un instituto jurídico marcado por el Derecho del Estado puede ser trasladado con pleno sentido al Derecho de la Unión.

\section{Erosión del Estado}

Esta nueva determinación de los institutos claves del Derecho público, su separación del anclaje estatal, no puede mantenerse sin repercutir en la comprensión jurídica de los Estados Miembros. En el curso de la definición de la Unión, se hace conveniente un nueva consideración de los Estados Miembros; a fin de cuentas, para la mayoría de las teorías, son un elemento integrante de la definición de la Unión, los Estados Miembros son un elemento central de la Unión. ¿Cómo se comprenden los cambios en el Estado-nación inducidos por el Derecho comunitario?

Los teóricos del Derecho del Estado se han ocupado intensamente de este tema desde el comienzo de los noventa ${ }^{33}$. En verdad, amplios círculos del Derecho

31. J. SHAw/A. WIENER: "The Paradox of the "European Polity", en State of the European Union 5: Risks, Reform, Resistance and Revival, Ed. Cowles/Smith, 2000.

32. Nota del traductor. en el trabajo original el autor incorpora citas y expresiones en inglés, francés y latín. Así se conservan en la traducción.

33. B. COTTIER: Staatsrechtliche Auswirkungen der Mitgliedschaft in den Europäischen Gemeinschaften, 1991; E. KLEIN: “Gedanken zur Europäisierung des deutschen Verfassungsrechts", en FS Stern, 1997, p. 1.301; D. SCHEUING: "Deutsches Verfassungsrecht und europäische Integration", EuR Beiheft 1/1997, p. 7. 
público alemán se han aplicado al estudio de la integración en virtud de este motivo. Las razones de fondo fueron la controvertida posición de Alemania en Europa a partir de la unión de los dos Estados alemanes, el logro de la plena soberanía, la desaparición de la amenaza del Este y, como motivo concreto, la profunda integración prevista mediante la unión monetaria ${ }^{34}$. El debate científico jurídico sobre la licitud de la ratificación del Tratado de Maastricht fue parte de las primeras controversias públicas sobre la integración europea ${ }^{35}$.

Los obstáculos constitucionales a la ratificación causaron una enérgica discusión: se constató una desestatalización de la República Federal por medio del Tratado de Maastricht, de dudosa constitucionalidad e incluso plenamente inconstituciona $^{36}$. Para algunos, el Tratado de Maastricht y la reforma del artículo 23 GG que lo posibilitó, tuvieron tal importancia que se deberían haber acometido no por los "pouvoirs constitués" sino por el "pouvouir constituant". Peter M. Huber sintetizó un convencimiento por entonces muy extendido, que el Tratado de Maastricht "Se había quedado por poco ante el umbral de lo que la Ley Fundamental considera como núcleo de la estatalidad", de manera que "el margen de actuación prácticamente se había consumido". Sólo el pueblo -como pouvouir constituantpodría facilitar una mayor integración ${ }^{37}$.

\section{La cuestión sobre la Constitución}

La figura del pouvoir constituant conduce a la más fructífera disputa en esta discusión: la cuestión sobre la Constitución. Durante muchos años el Tribunal de Justicia, con la aquiescencia de los Tribunales superiores y la doctrina alemana ${ }^{38}$, elaboró el carácter constitucional de los Tratados, los "constitucionalizó". La constitucionalización no se refiere tanto a la aproblemática función de los Tratados como estatuto organizativo de las Comunidades, sino - en virtud de la primacía y

34. Desde el punto de vista de las llamadas teorías realistas de las relaciones internacionales era de esperar una disolución o al menos una parcial desintegración de la Comunidad, W. Wessels: "Governance in the European Union before and after Maastricht", trabajo para la ECSA Sixth Biennial International Conference, p. 9.

35. Sobre la discusión en su dimensión europea M. FrankLIN/M. MARSH/L. McLaren: "Uncorking the Bottle: Popular Opposition to European Unification in the Wake of Maastricht", JCMSt 32 (1994), p. 455. En todo caso la importancia de la "la lucha sobre la contribución militar" de los años cincuenta puede ser invocada en este debate, sobre ello vid. Veröffentlichungen des Instituts für Staatslebre und Politik, Der Kampf um den Webrbeitrag, 1952, 1951, 1958.

36. Cfr por un lado D. MurswleK: "Maastricht und der Pouvoir Constituant", Der Staat 32 (1993), p. 161; H.H. Rupp: "Grundgesetzänderung durch völkerrechtlichen Vertrag -ein vernachlässigtes Problem des Maastrichter Vertrags", en FS Heymanns Verlag, 1995, p. 499; del mismo autor "Ausschaltung des Bundesverfassungsgerichts durch den Amsterdamer Vertrag?", JZ 1998, p. 213; por otro lado I. PERNICE: "Maastricht, der Staat und die Demokratie", Die Verwaltung 1993, p. 499, 474 y ss., 486 ;

J. SCHWARZE: "Das Staatsrecht in Europa", JZ 1993, pp. 585, 588 y ss.

37. P.M. HuBER: Maastricht-ein Staatstreich?, 1993, pp. 14, 48 y ss.

38. La doctrina alemana, tras dudas iniciales, se decicidió por la vía de Kiel (J.H. KAISER y P. BADURA: "Bewahrung und Veränderung demokratischer und rechtsstaatlicher Verfassungsstruktur in den internationalen Gemeinschaften (Kiel 1964), VVDStRL 23 (1996), pp. 1 y ss., 34 y ss.); para una visión general H.P. IPSEN: “Die europäische Integration in der deutschen Staatslehre”, FS Börner, 1992, p. 163. 
del efecto directo- a la Constitución de la sociedad europea, que vincula a los Estados Miembros y a los ciudadanos ${ }^{39}$. Eric STEIN, un autor americano, llamó la atención sobre el poder constituyente detentado por los jueces: "Tucked away in the fairyland Duchy of Luxembourg and blessed, until recently, with benign neglect by the powers that be and the mass media, the Court of Justice of European Communities has fashioned a constitutional framework for a federal-type Europe ${ }^{40}$.

El entendimiento de los Tratados como la Constitución de Europa es la imagen y la construcción explicativa más vigorosa del Derecho comunitario ${ }^{41}$. Métodos interpretativos y tendencias interpretativas, la autonomía del Derecho de la Unión, la vinculación al procedimiento de reforma y los límites a la reforma del Tratado, el dominio de los Estados Miembros sobre los Tratados, la disolución de la Unión o la licitud de la secesión singular: la respuestas de los "europeístas" a todas estas preguntas se fundan en el potencial argumentativo que ofrece la naturaleza constitucional de los Tratados. Joseph Weiler va más allá: "Constituticionalism is the DOS or Windows of the European Community" ${ }^{42}$.

Por tanto no puede sorprender que la ciencia jurídica alemana, en el contexto del debate sobre Maastricht, discutiera esta calificación de modo especialmente controvertido. Tal enfrentamiento se incardina en una notable tradición. Desde siempre, la ciencia jurídica ha edificado disputas políticas sobre cuestiones aparentemente técnico-conceptuales, cuya propia racionalidad era discutida y reformulada. Recuérdese la primera mitad del siglo XIX: la lucha sobre la división de poder entre la Corona y una cámara elegida (burguesía) fue presentada como un debate sobre el concepto jurídico de soberanía y su titular ${ }^{43}$. En la segunda mitad de ese siglo, el debate jurídico sobre el concepto de ley retrató el conflicto constitucional prusiano entre el Monarca y el Parlamento ${ }^{44}$.

39. Es clarificadora la comparación con la discusión paralela sobre la Carta de las Naciones Unidas, J. CRAwFORD: "The Charter of the United Nations as a Constitution", en The Changing Constitution of the United Nations, Ed. Fox, 1997, p. 3; B. FAßBBENDER: UN Security Council Reform and the Right of Veto. A Constitutional Perspective, 1998, pp. 25 y ss.

40. E. STEIn: "Lawyers, Judges and the Making of a Transnational Constitution", American Journal of International Law 75 (1981), p. 1. Desde este momento, este Journal, consecuentemente, dejó de publicar artículos sobre derecho del mercado interior. Expícitamente C-294/83, Les Verts/Parlament, (1986,1339,1365); Dictamen 1/1991, EWR I, (1991,I-6079,6102). El Abogado General M. LAGRANGE ya hablo en el caso Costa/E.N.E.L sobre una "verdadera Constitución" de las Comunidades europeas, C-6/64, (1964,1255,1289).

41. K. Amstrong: "Legal Integration: Theorizing the Legal Dimension of European Integration", JCMSt. 36 (1998), pp. 155, 161.

42. J.H. WEILER: "The Reformation of European Constitutionalism", JCMSt 35 (1997), p. 97; en las siguientes páginas se extiende en reconstruir el debate correspondiente, al que -según WEILER los autores alemanes sólo han incorporado aportaciones dogmáticas-, ibid, p. 128. La segunda edición en The Constitution of Europe, 1999, deja a un lado este añadido.

43. En detalle M. STOLLEIS: Geschichte des öffentlichen Rechts in Deutschland, 2. ${ }^{\circ}$ Vol, 1992, pp. 106 y ss. La novedosa y pragmática solución de aquella época por parte de la ciencia jurídica consistió en no atribuir la soberanía ni al pueblo ni al monarca, sino al Estado, solución que hoy ofrece enormes dificultades, C.F. OpHüls: "Staatshoheit und Gemeinschaftshoheit. Wandlungen des Souveränitätsbegriffs", en FS Heymanns Verlag, 1965, p. 519; W. PAUlY: "Souveräner Staat und Staatenverbindungen", en G. JELLINEK: Die Lebre von den Staatenverbindungen (1882), 1996, pp. IX y ss.

44. En detalle STOLLEIS (nota 43), pp. 370 y ss. 
La diferencia entre el debate actual sobre la Constitución europea y el pasado sobre la soberanía y la ley reside en las dificultades para describir hoy las líneas políticas en conflicto y los intereses en colisión. La versión que presenta la integración como una estrategia del capital europeo no ha impregnado a la academia ${ }^{45}$, aunque las preocupaciones reales sobre la redistribución a nivel europeo subsisten. Las ambiciones de poder institucional deberían representar su papel: el conflicto de los Tribunales superiores, inserto en la cuestión sobre la Constitución, ha de leerse como una lucha de poder enmascarada ${ }^{46}$. Asimismo se ha de sopesar un malestar difuso que resulta de la inmersión de las Constituciones de los Estado-nación en un mundo europeo desconocido, complejo, tecnocrático y frío ${ }^{47}$. Sin duda hay mucho en juego: la construcción de una Constitución europea socava la previa unidad política y jurídica que la Constitución del Estado-nación había producido y que el sistema conceptual en torno al Estado expresaba ${ }^{48}$. La visión opuesta establece que la historia de éxitos de la posguerra sólo se puede continuar cuando la Unión, como sistema político autónomo, se levante a la luz de los principios de la modernidad europea; esto exige la concepción de nuevas y complejas formas de asociación.

¿Dónde reside la función y el valor de la reformulación jurídico conceptual de este debate genuinamente político? Dos aspectos resultan importantes. Por un lado la ciencia jurídica introduce en el debate el valor y el peso de las instituciones existentes, así como la experiencia de su funcionamiento ${ }^{49}$; esto es especialmente válido si el discurso de la ciencia jurídica y de los juristas se comprende como un precipitado del discurso político-moral práctico ${ }^{50}$. En él emergen muchos aspectos que en la discusión política general no son expuestos de manera adecuada. Por otro lado, las exigencias de consistencia impuestas a la ciencia jurídica destapan las contradicciones, como cuando se sostiene a la par el Estado federal europeo y el tradicional Estado-nación.

La discusión sobre el carácter constitucional permite desarrollar en el Derecho comunitario primario numerosos elementos nucleares y tradicionales del Derecho público. En esta línea ciertas posiciones llaman la atención, en primer lugar, sobre la equivalencia funcional entre disposiciones de las Constituciones estatales y complejos normativos del Derecho comunitario primario ${ }^{51}$. Las posiciones en contra

45. J. GALTUNG: Kapitalistische Großmacht Europa oder die Gemeinschaft der Konzerne?, 1973.

46. M. HEINTZEN: "Die Herrschaft über die Europäischen Verfassungsverträge -Bundesverfassungsgericht und Europäischer Gerichtshof auf Konfliktkurs?», $A \ddot{O} R 119$ (1994), p. 564; respecto a estas relaciones K. ALTER: "Explaining National Court Acceptance of European Court Jurisprudence" y A. STONE SwEET: "Constitutional Dialogues in the European Community", ambos en: The European Courts and National Courts, Ed. Slaughter/Stone Sweet/Weiler, 1999, pp. 227, 305.

47. "Most profound" expuesto por WeILer (nota 42), pp. 108 y ss.

48. M. KAUFMANN: "Permanente Verfassunggebung und verfassungsrechtliche Selbstbindung im europäischen Staatenverbund", Der Staat 36 (1997), pp. 521, 523 y ss.

49. SCHMIDT-ABMANN (nota 11), pp. 4 y ss.

50. Al respecto nota 19.

51. KuTSCHER (nota 9), pp. I-32 y ss.; P. PESCATORE: "Die Gemeinschaftsverträge als Verfassungsrecht" en FS Kutscher, 1981, p. 319; R. BERNHARDT: "Quellen des Gemeinschaftsrechts: Die "Verfassung" der Gemeinschaft", en 30 Jabre Gemeinschaftsrecht, Ed. Kommission, 1983, p. 77; F. MancINI: "The Making of a Constitution", CMLR 26 (1989), p. 595; G.C. RODRíGUEZ IGLESIAS: "Der Gerichtshof der Europäischen Gemeinschaft als Verfassungsgericht", EuR 1992, p. 225; U. EverLING: "Zur Stellung der 
descansan en diferentes concepciones constitucionales ${ }^{52}$. Así, algunos ven una necesaria correspondencia entre la Constitución y el Estado. Otros identifican determinadas normas (por ejemplo: competencia-competencia $\left.{ }^{53}\right)^{54}$ o situaciones de hecho (sobre todo: un espacio público y político unitario o incluso un pueblo europeo) como condiciones para adquirir el carácter constitucional, las cuales no son satisfechas a nivel europeo ${ }^{55}$.

La tradición constitucional europea permite hacer una parada decisiva en el último punto y preguntarse sobre la razón de ser última del Derecho comunitario primario como Constitución, es decir, preguntarse sobre el poder constituyente. Joseph Kaiser ya vio este problema en 1964 y constató un poder constitucional atlántico, cuyo contorno aún permanece impreciso ${ }^{56}$. Lo cual no es sorprendente, pues la ciencia del Derecho Constitucional ofrece sobre este concepto límite ${ }^{57}$ poca certeza. Está claro que no reside en el Tribunal de Justicia o en los Jefes de Estado, que controlan la ratificación de los Tratados, como es habitual en el Derecho internacional. Sin discusión se niega que el poder constituyente lo detente el Parlamento europeo ${ }^{58}$. La opinión mayoritaria ubica el poder constituyente en los Estados miembros ${ }^{59}$. Realmente ciertos procedimientos permiten otra versión: en el caso de la reforma de los Tratados y con ella la reforma de la Constitución, los ciudadanos manifiestan su aprobación a través de los procedimientos previstos en las distintas Constituciones de los Estados Miembros, de modo parecido a como ocurrió con la entrada en vigor de la Ley Fundamental en 1949. La dimensión

Mitgliedstaaten der Europäischen Union als "Herren der Verträge»", en FS Bernhardt, 1995, p. 1.161; R. STEINBERG: "Grundgesetz und Europäische Verfassung", ZRP 1999, p. 365; un análisis de las distintas comprensiones en L.M. Dízz PiCAzO: "Reflexiones sobre la idea de Constitución europea", Revista de instituciones europeas 1993, p. 533; F. SNYDER: "General Course on constutional Law of the European Union", en Collected Courses of the Academy of European Law, 1995-Vol. VI-1, p. 41, Ed. Academy of European Law, 1998.

52. P. KIRCHHOF: "Der deutsche Staat im Prozess der europäischen Integration", en Handbuch des Staatsrechts, Ed. Isensee/Kirchhof, Vol. 7, 1992, \& 181, párrafo 33, 37 y ss.; A. RANDELZHOFER: "Souveränität und Rechtsstaat: Anforderungen an eine Europäische Verfassung", en Der Rechtsstaat am Ende?, 1995, pp. 123, 124 y ss.

53. Nota del traductor: el original utiliza el término alemán "Kompetenz-Kompetenz". Este término enlaza con la teoría general del Estado de corte germánico, que durate la segunda mitad del siglo XIX elaboró el concepto jurídico de Estado a partir de la capacidad de éste para autoobligarse jurídicamente, para poner límites a su poder, en fin, para configurar sus competencias: el Estado tenía la competencia para determinar sus competencias, de ahí el término "Kompetenz-Kompetenz".

54. C. KoENIG: "Anmerkungen zur Grundordnung der Europäischen Union und ihrem fehlenden "Verfassungsbedarf", NVwZ 1996, pp. 549, 551; desde una perspectiva crítica P. LERCHE: "KompetenzKompetenz" und das Maastricht-Urteil des Bundesverfassungsgerichts", en FS Heymanns Verlag, Verfassungsrecht im Wandel, Ed. Ipsen, 1995, p. 409.

55. D. GRIMM: "Braucht Europa eine Verfassung?", JZ 1995, pp. 581, 586.

56. KAISER: "Zur gegenwärtigen Differenzierung von Recht und Staat. Staatstheoretische Lehren der Integration", ÖstZfÖffR X (1959/60), pp. 413, 419.

57. E.-W BÖCKENFÖRDE: "Die verfassunggebende Gewalt des Volkes -ein Grenzbegriff des Verfassungsrechts", en su libro Staat, Verfassung, Demokratie, 1991, p. 90.

58. M. HiLF: "Wege und Verantwortlichkeiten Europäischer Verfassunggebung", en Eine Verfassunggebung für Europa, Ed. Schwarze/Bieber, 1984, pp. 253, 358.

59. Cfr. únicamente M. Zuleeg: "Der rechtliche Zusammenhalt in der Europäischen Verfassunggebung", en Die Europäische Union als Rechtsgemeinschaft, Ed. Blomeyer/Schachtschneider, 1995 ; pp. 9, 12. 
práctica de esta discusión no se ha de infravalorar: bajo su luz se pone de manifiesto la inadecuación del procedimiento recogido en el artículo 48 TUE, previsto como mera conferencia intergubernamental, y la necesidad de prestar más atención a su dimensión de poder constituyente mediante una mayor incardinación del ciudadano europeo ${ }^{60}$.

Aunque el debate continua, se puede realizar un balance provisional. El análisis del Derecho primario desde el parámetro de la doctrina constitucional elaborada para el Estado ha significado - lo que es un primer resultado positivo- los estímulos, las especialidades y los déficit del Derecho primario. También ha ocurrido un proceso de aprendizaje recíproco, de modo que los frentes ya no son tan duros como al principio del debate. Se ha señalado cómo las voces que tras la sentencia del TCFA sobre el Tratado de Maastricht excluyeron por prácticamente imposible cualquier desarrollo ulterior de la integración ${ }^{61}$, no han pedido la palabra $^{62}$ en el proceso de ratificación del Tratado de Amsterdam -sin apreciar como ha profundizado la integración este Tratado ${ }^{63}$. Incluso ya no se pone en duda la posibilidad de una integración más profunda ${ }^{64}$.

La clasificación de las relaciones recíprocas entre la Constitución de la Unión y las Constituciones nacionales parece ser el nuevo gran tema. Los profesores de Derecho público alemán se ocuparán de este tema en otoño del año 2000. Si de esta reunión no se desprende que la mayoría no discute el carácter constitucional del derecho primario, no existirá todavía la posibilidad de un recto entendimiento del Derecho primario. Más bien se dibujan modelos diametralmente distintos. Por un lado concibe Ingolf Pernice una unión de Constituciones ${ }^{65}$, que implica en

60. R. BIEBER: "Verfassungsentwicklung und Verfassungsgebung in der Europäischen Gemeinschaft", en Staatswerdung Europas?, Ed. Wildenmann, 1991, p. 393; B. DE WITTE: "Rules of Change in International Law: How Special is the European Community?,, NYIL 25 (1994), p. 299; del mismo autor: "International Agreement or European Constitution?", en Reforming the Treaty on European Union, Ed. Winter/Curtin/Kellermann/de Witte, 1996, p. 3.

61. C. KIRCHNER/J. HAAS: "Rechtliche Grenzen für Kompetenzübertragungen auf die Europäische Gemeinschaft, $J Z$ 1993, p. 760 ; añádase la perspectiva esceptica de K.M. MEessen: «Maastricht nach Karlsruhe», NJW 1994, pp. 549, 555.

62. M. PECHSTEIN: "Amsterdamer Vertrag und Grundgesetz", DÖV 1998, p. 589.

63. S. LANGRISH: "The Treaty of Amsterdam: Selected highlights", ELR 23 (1998), p. 3; A. v. BogdANDY: Supranationaler Föderalismus als Idee und Wirklicbkeit einer neuen Herrschaftsform, 1999, pp. $11 \mathrm{y}$ ss.

64. Cfr. BVerfGE 98, 350, 372: "en atención al continuo desarrollo de la Unión Europea"; P. KIrCHHOF no ve obstáculos constitucionales a una profundización motivada por la inclusión de un catálogo de derechos fundamentales, la extensión de la decisión mayoritaria en el Consejo y la codecisión del Parlamento Europeo, FAZ 11 de Septiembre 1999, p. 5.

65. Nota del traductor. el texto original utiliza el término "Verfassungsverbund" elaborado por I. Pernice. La explicación de este término, unida al que aparecerá más adelante "Staatenverbund" y que hemos traducido como unión de Estados precisan de una aclaración. Sabido es que la Teoría del Estado alemana venía trabajando con dos conceptos clásicos "Staatenbund"-traducido al español como Confederación- y "Bundesstaat" -traducido al español como Estado federal o Federación- En esta tradición, Paul Kirchhof, a la hora de conceptualizar la Comunidad europea, utiliza, jugando con los anteriores conceptos, el inédito término de "Staatenverbund" con la intención, más que nada, de dejar claro que la Comunidad es algo más que una Confederación (de ahí, a nuestro parecer, la partícula de refuerzo "ver") y algo menos que una Federación (de ahí el sustantivo Estado en plural). Frente a este concepto, pero también jugando con él, I. Pernice ha elaborado posteriormente el término Verfassungsverbund, donde quiere resaltar a la Constitución como elemento central de su teoría, oponiéndose a Kirchhof que hacía destacar el Estado. 
su sentido final relaciones federo-estatales ${ }^{66}$. Por otro lado están las concepciones que divisan el núcleo constitucional europeo en las cláusulas de integración de las Constituciones nacionales ${ }^{67}$, de modo que discuten la autonomía constitucional de la Unión.

\section{Fragmentación y europeización del Derecho nacional}

En el curso de la construcción del ordenamiento jurídico comunitario se acrecienta la fragmentación de los ordenamientos jurídicos nacionales, los cuales incluso en su parte remanente son a menudo la sola trasposición de Derecho comunitario. Si el Derecho nacional que resulta del proceso nacional de formación de la voluntad es un instrumento esencial para la integración de la sociedad naciona ${ }^{68}$, se ha de temer un extrañamiento y una desintegración de la sociedad: el Derecho comunitario es resultado de un proceso europeo de formación de la voluntad en el que se han de satisfacer otros intereses, valores y preferencias, más allá de los alemanes. Desde el punto de vista práctico, no es cuestión poco dramática plantearse en qué medida pueden integrarse las innovaciones inducidas por el Derecho comunitario en el tejido del Derecho nacional, con las menores fricciones posibles, garantizando su integridad sistemática.

Las implicaciones de la fragmentaria validez del ordenamiento jurídico alemán para la integración de la sociedad han sido poco investigadas ${ }^{69}$. Por el contrario, el desenvolvimiento del Derecho nacional bajo el parámetro del Derecho supranacional, las consecuencias de la desnacionalización del Derecho y la tensión sistemática han experimentado una gran atención. Los académicos del Derecho privado tienen la ventaja de poder apoyarse en una larga tradición de Derecho comparado y unificación jurídica internacional ${ }^{70}$. La dogmática alemana del Derecho administrativo elevó, en los noventa, a categoría central la dimensión supranacional de su objeto y desde ese momento lo estudia con especial dedicación ${ }^{71}$.

66. En detalle el epígrafe II 3.

67. M. KAUFMANN (nota 48), 534 y ss.; del mismo autor: "Integrierte Staatlichkeit als Staatsstrukturprinzip", $J Z$ 1999, p. 814; en el mismo sentido A. SCHMITT-GLAESER: Grundgesetz und Europarecht als Elemente europäischen Verfassungsrechts, 1999, p. 5.

68. Esta es una descripción habitual, cfr. Zippelius: Rechtsphilosophie, 1982, p. 191.

69. Anticipándose J.H. KAISER: "Zur gegenwärtigen Differenzierung von Recht und Staat. Staatstheoretische Lehren der Integration", ÖstZfÖffR X (1959/60), p. 413, 415; A. v. BogDANDY: "Zweierlei Verfassungsrecht", Der Staat 39 (2000); con una intención de totalidad W. VAN GERVEN: "Toward a coherent constitutional system within the European Union", Zentrum für Europäisches Wirtschaftsrecht, Vol. 55 (1995), p. 12.

70. H. KöтZ: “Rechtsvereinheitlichung -Nutzen, Kosten, Methoden, Ziele», RabelsZ 50 (1986), p. 1; O. REMIEN: "Denationalisierung des Privatrechts in der Europäischen Union?", ZfRV36 (1995), p. 116; como trabajo de referencia en torno a los específicos efectos del TCE sobre el Derecho privado, su construcción y cuarenta años de intensiva investigación, E. STEINDORfF: EG-Vertrag und Privatrecht, 1996. Sobre la armonización del derecho de obligaciones como ámbito nuclear del Derecho civil, S. GRUNDMANN: Europäisches Schuldvertragsrecht: das europäische Recht der Unternebmensgeschäfte, 1999.

71. Se han de mencionar el trabajo de habilitación de M. BRENNER: Der Gestaltungsauftrag der Verwaltung in der Europäischen Union, 1996; T. v DANwITZ: Verwaltungsrechtliches System und Europäische 
Este debate dialoga inevitablemente con el destino de la estatalidad alemana -aunque más bien implícitamente-, si se tiene en cuenta la tradicional reciprocidad entre Estado y Administración ${ }^{72}$.

El espacio de apreciaciones es amplio ${ }^{73}$. Algunos observan un "extranjerismo" del Derecho administrativo alemán ${ }^{74}$, incluso una situación de "ocupación " ${ }^{75}$. Otros saludan los procesos y sugerencias comunitarias con el fin de modernizar el Derecho administrativo nacional ${ }^{76}$. Desde el punto de vista pragmático y formativo es orientadora la concepción desarrollada por Stefan Kadelbach de un Derecho administrativo comunitario nacional específico, que diagnostica y recomienda un desarrollo dual del Derecho administrativo alemán, lo que aminora considerablemente la presión de la adaptación ${ }^{77}$.

De especial importancia es una nueva línea de investigación que se ocupa jurídicamente de los vínculos administrativos entre las Administraciones de los distintos Estados Miembros y los órganos de la Unión ${ }^{78}$, de manera análoga a la investigación politológica, que desde hace tiempo estudia con especial esfuerzo la interconexión administrativa de los distintos niveles ${ }^{79}$. Un importante planteamiento politológico ve en esta imbricación, funcionalmente, el desarrollo de una Administración única, que no opera exclusivamente en el nivel estatal ${ }^{80}$. Este planteamiento presenta con especial claridad los retos de la dogmática administrativista: desde los elementos comunes del Derecho nacional y supranacional debe construir una dogmática que responda a todos los nuevos retos que plantee la dirección y control de la acción administrativa. Nuevo debate de Derecho administrativo que corre paralelo al debate de Derecho constitucional sobre la armonía de la Constituciones europeas y nacionales. Es de esperar que ambos debates creen concepciones que permitan comprender adecuadamente ese todo, aún innominado, compuesto por la Unión y los Estados Miembros.

En el contexto de este debate sobre la europeización del Derecho nacional están siendo discutidas intensamente las competencias del Tribunal de Justicia, pues

Integration, 1996, A. HATJE: Die gemeinschaftsrechtliche Steuerung der Wirtschaftsverwaltung, $1998 ; \mathrm{S}$. KADELBACH: Allgemeines Verwaltungsrecht unter europäischem Einfluß, 1999; y la fundamental habilitación de M. ZulEEG: Das Recht der Europäischen Gemeinschaften im innerstaatlichen Bereich, 1969.

72. A. DE TOCQUeVILL: Der alte Staat und die Revolution (1856), 1978, p. 35 y ss., 190 y ss., E. FRIESENHAHN: "Parlament und Regierung im modernen Staat", VVDStRL 16 (1958), p. 9, 12.

73. Sobre las etapas de desarrollo del debate E. SchmidT-AßMANN: "Strukturen des Europäischen Verwaltungsrechts: Einleitende Problemskizze", en Strukturen des Europäischen Verwaltungsrechts, Ed. E. Schmidt-Aßmann/Hoffmann-Riem, 1999, p. 9.

74. Para un resumen v. DANwitz (nota 71), pp. 398 y ss.

75. J. SALZWEDEL/M. ReINHARDT: "Neuere Tendenzen im Wasserrecht", NVwZ 1991, pp. 946, 947.

76. U. ERICHSEN: "Das Recht auf freien Zugang zu Informationen über die Umwelt", NVwZ 1992, pp. $409,419$.

77. Como precursor KadelBaCh (nota 71).

78. Como trabajo pionero las contribuciones en SCHMIDT-AßMANN/HoFFMANN-RiEM (nota 73).

79. A. HÉRITIER/S. Mingers/C. KNILL/M. BECKA: Die Veränderung von Staatlichkeit in Europa, 1994; T. KOENIG/E. RIEGER/H. SCHMITT: Das europäische Mebrebenensystem, 1996.

80. W. WessELs: "Comitology: fusion in action: Politico-administrative trends in the EU system", Journal of European Public Policy 5 (1998), p. 209; del mismo autor: "Verwaltung im EG-Mehrebenensystem: Auf dem Weg zur Megabürokratie?", en Europäische Integration, Ed. Jachtenfuchs/KohlerKoch, 1996, pp. 165, 169 y ss. 
el desplazamiento del Derecho nacional se debe en parte considerable al desarrollo jurisprudencial del Derecho. En el objeto de esta discusión se manifiestan con claridad los intereses de los distintos sistemas científicos. La dogmática anglosajona analizó al TJ, sobre todo, como actor político ${ }^{81}$, mientras que la dogmática en lengua alemana se ocupó prioritariamente, por el contrario, de las condiciones que licitan la creación judicial de Derecho ${ }^{82}$. Tal discusión es ante todo relevante desde el punto de vista práctico, ya que la validez de la creación judicial del Derecho es negada en la República Federal ${ }^{83}$. Sin embargo, en esa discusión es difícil encontrar puntos de enlace, debido a que en otros ordenamientos jurídicos apenas se efectúa la distinción científico jurídica entre interpretación y creación judicial de Derecho: "interpretation" O "justification" abarca a ambas ${ }^{84}$. Aquí se muestran los esfuerzos de interpretación que aún han de rendirse en el discurso europeo.

\section{El Derecho como instrumento de integración en manos de un titular NO ESTATAL DE PODER PÚBLICO ${ }^{85}$}

Los apartados anteriores han expuesto debates en los que los fundamentos del Derecho comunitario se deducen de la situación de tensión entre el Estado-nación y un titular supranancional de dominio. Si bien, es propio de la peculiaridad de la ciencia del Derecho comunitario que la reflexión sobre los fundamentos no se limite a este ámbito. Casi ninguna otra discusión es más importante que la reconsideración de su objeto central: el Derecho. Con el Derecho de la Unión normas no estatales pasan a ser objeto normal de lo jurídico. Se ha abandonado de pleno la tesis defendida en los inicios de la integración por la cual el Derecho comunitario se aplicaba en virtud de su transformación en Derecho nacional ${ }^{86}$. En el curso de la integración no sólo se construye un mercado sin $\operatorname{Estado~}^{87}$ y un sistema de gobierno sin

81. Inició el debate a nivel internacional H. RASMUSSEN: On Law and Policy in the European Court of Justice, 1986; A.-M. BuRLEY/W. MATTLI: "Europe Before the Court: A Political Theory of Legal Integration", International Organization 47 (1993), p. 1; A. STONE: "Constitutional Dialog in the European Community", EUI Working Papers RSC 1995; WEILER: The Constitution of Europe, 1999, pp. 188 y ss.

82. R. BIEBER/G. REss: Die Dynamik des Gemeinschaftsrechts: die Auslegung des Europäischen Gemeinschaftsrechts im Lichte nachfolgender Praxis der Mitgliedstaaten und EG-Organe, 1987; C.D. BORCHARDT: "Richterrecht durch den EuGH", en GS Grabitz, 1995, p. 29; J. UkROw: Richterliche Rechtsfortbildung durch den EuGH, 1995; U. EvERLING: "Richterliche Rechtsfortbildung in der Europäischen

83. Últimamente R. ScHOLz. "Zum Verhältnis von europäischem Gemeinschaftsrecht und nationalem Verwaltungsverfahrensrecht", $D O ̈ V 1998$, pp. 261, 264 y ss.; en el mismo sentido A. JuNKER: "Der EuGH im Arbeitsrecht -Die schwarze Serie geht weiter", NJW 1994, pp. 25-27. 84. Cfr. J. BENGOTEXEA: The Legal Reasoning of the European Court of Justice, 1993, pp. 112 y ss.,
141 y ss.; KuTSCHER (nota 9); pp. I-7 y ss.

85. Nota del traductor. el texto original utiliza el término "Hoheitsträger", habitualmente traducido como titular de poder soberano. En esta traducción se ha preferido la acepción titular de poder público.

86. H. BüLCK: "Zur Systematik der Europäischen Wirtschatsgemeinschaften", Berichte der Deutschen Gesellschaft für Volkerrecht 3 (1959), pp. 66, 96 (en nota 95); otras ejemplos en E. GRABITZ: Gemeinschaftsrecht bricht nationales Recht, 1996, p. 13.

87. C. JOERGES: “Staat ohne Markt?", en Staatswerdung Europas?, Ed. Wildenmann, 1991, p. 225; P. KAPTEYN: The Stateless Market, 1996. 
Estado $^{88}$, sino también un Derecho sin Estado, que incluso tiene como función superar la ordenación estatal del Continente.

En virtud de la reelaboración de las categorías fundamentales de la ciencia jurídica, se ha de reflexionar sobre la reciprocidad de los conceptos Estado y Derecho en su entendimiento tradicional: el Derecho se define esencialmente a través de la coacción y el Estado es la organización social que detenta el monopolio legítimo de la fuerza ${ }^{89}$. Esta reciprocidad se ha llevado hasta el punto de ver en el concepto Estado de Derecho un sin sentido ${ }^{90}$. Pero la Unión es una organización de dominio sin poder coactivo, en tanto que el monopolio de éste reside en los Estados miembros. ¿Por qué se cumple entonces el Derecho de la Unión?

El debate tradicional del Derecho internacional -aún abierto-, muestra la dimensión de este reto teórico ${ }^{91}$. Según el entendimiento dominante, la naturaleza jurídica de las normas de la Unión se apoya en el poder coactivo nacional, lo que provoca su dependencia del Derecho de los Estados Miembros ${ }^{92}$. Pero esto no explica la obediencia jurídica de los Estados Miembros, distinta a la propia del Derecho internacional. Por lo demás, la versión contraria imputa a la Unión el poder coactivo nacional, pues los Estados Miembros en virtud del Derecho de la Unión -art. 10 TCEestán obligados a la aplicación de este ordenamiento jurídico. La idea de que los órganos estatales titulares de poder público son funcionalmente órganos comunitarios al implementar el Derecho de la Unión es una idea bastante extendida ${ }^{93}$. Sin embargo, la opinión dominante considera que el poder de dominio y coacción utilizado por los órganos estatales tiene origen estatal ${ }^{94}$, en la aplicación del Derecho comunitario se ejerce poder coactivo estatal, no poder coactivo de la Unión. El Derecho de la Unión es el Derecho de una organización sin poder coactivo.

La dogmática comunitaria apenas se ha dedicado a este tema general, si bien en los sesenta un aspecto se investigó con especial intensidad: la razón de validez del Derecho supranacional en el ámbito de dominio de los Estados Miembros. La comprensión estatalista hace depender la validez del Derecho de la Unión en el ámbito soberano de los Estados Miembros de una orden de aplicación nacional ${ }^{95}$.

89. H. WAlLACE: "Government without Statehood", en Policy-Making in the European Union, 3." Ed. H. Wallace/W. Wallace, 1996, pp. 439 y ss.

90. H. HORN: Einfübrung in die Rechtswissenschaft und Rechtsphilosphie, 1996, p. 3; O. HÖFFE: Politsche Gerechtigkeit: Grundlegung einer Philosophie von Recht und Staat, 1987, p. 25; KAUFMANN (nota 48), pp. 423 y ss.; K. RÖHL: Rechtssoziologie, 1987, pp. 209, 213 y ss., 220.

91. H. KELSEN: Reine Rechtslebre, 2.a Ed., 1960, p. 314.

92. Al respecto la visión general de W. Graf VITZTHum: "Begriff, Geschichte und Quellen des Völkerrechts", en su libro Völkerrecht, 1998, párrafo 61 y ss.; precursor con atención al ius cogens S. KADFLBACH: Zwingendes Völkerrecht, 1992, pp. 130 y ss., en especial pp. 160 y ss.

93. Una posición en este sentido de teoría general del Derecho Internacional A. D'AmANTO: International Law: Process and Prospect, 1987, pp. 1 y ss.

94. Cfr. S. CASSESE: "Der Einfluß des gemeinschaftsrechtlichen Verwaltungsrechts auf die nationalen Verwaltungsrechtssysteme», Der Staat 1994, pp. 25, 26.

95. Con la consecuencia de que los jueces nacionales garantizan la tutela, E. SCHMIDT-AßMANN, "Introducción", pp. 108 y ss., en SCHOCH/PiETZNER/SCHMidT-AßMANN: VwGO-Kommentar, adaptación de marzo 1999. I. Pernice, nota 123.

96. Para los argumentos pro y contra T. ScHILLING: "The Autonomy of the Community Legal Order", Harvard International Law Journal 37 (1996), pp. 389 y ss., y J.H. WeILER/U. HALTERN: "Response: The Autonomy of the Community Legal Order", HIJL 37 (1996), p. 411. 
La principal consecuencia es el posible control del Derecho supranacional por los tribunales nacionales ${ }^{96}$, si bien se han de limitar a contrastar su adecuación al contenido esencial de los derechos fundamentales nacionales y a garantizar el respeto de las competencias de la Unión. Respecto a la autonomía del Derecho comunitario existen distintas teorías. Desde el punto de vista histórico es especialmente importante la teoría del acto colectivo de Hans Peter Ipsen, por la cual los distintos pueblos europeos tras sus correspondientes procedimientos constitucionales construyen mediante un acto común un poder público nuevo, directo e independiente ${ }^{97}$. En discusiones posteriores, la pregunta sobre la autonomía se ha vinculado al carácter constitucional de los Tratados, pues la Constitución es razón de validez de un ordenamiento jurídico ${ }^{98}$. La aceptación del carácter constitucional del Derecho primario conduce a la validez autónoma del Derecho de la Unión frente a sus sujetos jurídicos ${ }^{99}$.

La marginación en el debate constitucional de la construcción explicativa ipseniana muestra que una construcción exclusivamente positivo-procedimental no es suficiente para fundamentar la validez autónoma. Sin embargo, no muchos emplean la mirada retrospectiva sobre las grandes teorías de la filosofía del Derecho. Es sorprendente que de las grandes teorías filosófico jurídicas, sea la habermaniana teoría del discurso la que haya gozado de una pronunciada recepción, sin duda más allá del ámbito lingüístico alemán ${ }^{100}$. Christian Joerges, Dieter Wolf y Michael Zürn desarrollan desde estos fundamentos valiosas aportaciones sobre la específica naturaleza del Derecho comunitario, entre el Derecho internacional y el Derecho del Estado. Separan la naturaleza jurídica del Derecho de la Unión del armazón coactivo y la vinculan al proceso normativo, a su capacidad para producir legitimidad. Esto conduce al previsible resultado de atribuir al Derecho comunitario, en virtud de su escasa publicidad, una "una reducida calidad jurídica, en comparación con la de la ley en el Estado democrático de derecho»101.

96. P. KIRChHOF (nota 52), párrafo 63 y ss.; sobre la "metáfora del puente" W. Graf VITZTHUM: "Gemeinschaftsgericht und Verfassungsgericht -rechtsvergleichende Aspekte", JZ 1998, p. 161; de modo similar F. RUBio LLORENTE: "La constitución española y el tratado de Maastricht", en su libro La forma del poder, 1993, pp. 175 y ss.; en esta línea también G. HIRSCH: "Kompetenzverteilung zwischen EuGH und nationaler Gerichtsbarkeit", NVwZ 1998, pp. 907, 908 y ss.

97. IPSEN (nota 20), pp. 58 y ss.; como figura jurídica de dimensión comunitaria G.C. RODRíGUEZ IGLESIAS: "Gedanken zum Entstehen einer Europäischen Rechtsordnung", NJW 1999, pp. 1, 3.

98. K. Hesse: Grundzüge des Verfassungsrechts der Bundesrepublik Deutschland, 20.a Ed., 1995, párrafo 35; R. Kovar: "La contribution de la Cour de justice à l'édification de l'ordre juridique communautaire", en Collected Courses of the Academy of Europea Law, 1993-Vol. IV-1, pp. 15, 21 y ss., Ed. Academy of European Law, 1995. Schilling (nota 92), pp. 389, 395 y ss.

99. Kovar (nota 94), pp. 34 y ss.

100. D. CuRTIN: Postnational Democracy. The European Union in Search of a Political Philosophy, 1997; J. SHAw: "Citizenship of the Union", en Collected Courses of the Academy of European Law, 1995-Vol. VI1, p. 237, Ed. Academy of European Law; del mismo autor: "Postnational constitutionalism in the European Union", JEPP 1999, pp. 579 y ss.; P. CRAIG: "The Nature of the Community: Integration, Democracy and Legitimacy", en CRAIG/DE BurCa (nota 26), pp. 26 y ss.; la posición pro comunitaria de J. HaBermas (cfr. su trabajo: "Remarks on Dieter Grimm's "Does Europe Need a Constitution", ELJ 1 (1995), p. 303) no es fácilmente deducible de sus presupuestos filosóficos, U. DI FABIO: Das Recht offener Staaten, 1999, p. 3.

101. JOERGES (nota 17), pp. 86 y ss.; M. ZÜRN/D. WOLF: "Europarecht und internationale Regime: zu den Merkmalen von Recht jenseits des Nationalstaates", en Recht jenseits des Staates, 
A la ciencia jurídica le es mayoritariamente extraña esta estrecha ligazón entre legalidad y legitimidad, naturaleza jurídica y exigencias político jurídicas, factidad y validez. De modo que existen otros intentos para explicar la relación entre el Derecho nacional y el comunitario. Wolf-Dietrich Grussmann ${ }^{102}$ presenta un esbozo en la tradición de la escuela vienesa del Derecho, por el cual el ordenamiento jurídico comunitario, en atención a la Teoría pura del Derecho, se funda en una norma fundamental, de modo que numerosas características del Derecho de la Unión se modelan en el marco de una "gran teoría". Sin embargo, este proyecto no ha encontrado demasiados adeptos ${ }^{103}$. Además, existen proyectos, dentro de la teoría de sistemas, que, sin embargo, no han conducido a construcciones jurídicas específicas ${ }^{104}$. Si se piensa que actualmente Luhmann reflexiona sobre un sistema jurídico ordenador del mundo, surge la duda sobre si la teoría de sistemas está en la situación de poder explicar la especificidad del Derecho de la Unión ${ }^{105}$.

La rama británica del positivismo institucionalista ha logrado una sobresaliente y profunda contribución teórica ${ }^{106}$. Con Neil MacCormick se ha recibido a un prominente teórico del Derecho de la Unión y la compilación de sus numerosos trabajos ha compuesto un esbozo teórico-jurídico general ${ }^{107}$. El positivismo institucional pretende unir en un todo el entendimiento práctico del Derecho, los conocimientos sociológicos y la teoría del pragmatismo, lo cual permite una convincente separación del Derecho, el Estado y la coacción, así como concebir el pluralismo de varios ordenamientos jurídicos -lo que es importante para posteriores preguntas. Otros trabajos muestran a qué resultados jurídicos puede llegar este cúmulo de concepciones político teóricas, análisis dogmáticos y datos empíricos ${ }^{108}$.

El Derecho de la Unión necesita de la ciencia jurídica no sólo en atención a las dudas sobre su carácter estatal o no. También su función es singular, por cuanto que es instrumento de transformación social y política en una medida desconocida para una sociedad democrática. A este respecto, el Derecho comunitario no estabiliza las relaciones de poder, las relaciones sociales y las expectativas normativas, sino que las transforma en vistas a un futuro europeo común. Si se reflexiona sobre la centralidad del Estado-nación en casi todas las relaciones sociales,

Ed. Neyer/Wolf/Zürn, ZERP-Diskussionspapier 1/99, 1999, pp. 1, 14 y ss., 22 (donde se recoge la cita).

102. W.-D GrussmanN: "Grundnorm und Supranationalität", en Auf dem Wege zu einer Europäischen Staatlichkeit, Ed. v. Danwitz/Heintzen/Jestaedt/Korioth/Reinhardt, 1993, p. 47.

103. Esta concepción es incluso discutida por un autor que trabaja en la tradición kelseniana, T. Schiluing: Rang und Geltung, 1994, pp. 183 y ss.

104. Cfr. di FABIO (nota 97), pp. 139 y ss.; K.-H LADEur: “Towards a Legal theory of Supranationality: The Viability of the Network Concept", ELJ 3 (1997), p. 33; G. TeUBner: Global Law withouth a State, 1996.

105. Luhmann (nota 4), p. 572; en particular contraste, debido a su condición de teórico de sistemas H. Willke: Die Ironie des Staates, 1992, pp. 369 y ss.

106. Fundamentalmente N. MACCORMICK/O. WEINBERGER: Grundlagen des Institutionalistischen Rechtspositivismus, 1985.

107. N. MACCORMick: Questioning Sovereignty. Law, State, and Nation in the European Commonwealth, 1999.

108. BeNGOETXEA (nota 81); D. CURTIN/I. DeKKER: "The EU as "Layered" International Organization", en CRAIG/De BurCa (nota 26), pp. 83, 86 y ss.; R. Wessel: The European Union's Foreign and Security Policy, 1999. 
el Derecho comunitario se presenta como instrumento de un plan, en última instancia revolucionario. En este sentido, la función de integración del Derecho supranacional va más allá de lo que se entiende en las comunidades estatales sobre la función de integración y de transformación del Derecho.

A esta constatación se añaden distintos intereses intelectuales. Así se examina en qué medida el Derecho supranacional supone un verdadero instrumento para la producción de una nueva realidad social y política: donde encontramos posiciones que enfrentan perspectivas escépticas ${ }^{109}$. Numerosos estudios se ocupan de comparar la integración en los Estados Unidos: en esta comparación, por un lado, se puede comprender la particular importancia del Derecho y la jurisprudencia de un Tribunal central, por otro se muestran con claridad los límites más allá de los cuales sólo procesos explícitos pueden impulsar la integración de sociedades ${ }^{110}$.

La orientación del Derecho comunitario hacia la integración es al mismo tiempo el talón de Aquiles de este cuerpo jurídico: su "unidimensionalidad" y "unilateralidad" es un punto débil significativo ${ }^{111}$. Sólo paulatinamente se ha liberado de esta finalidad dominante para volverse multifuncional, de modo que pueda satisfacer las tareas múltiples y cambiantes que la ciencia jurídica reconoce como propias en el sistema jurídico de una sociedad compleja ${ }^{112}$. Esta liberación se liga a la reflexión sobre la configuración, finalidad y legitimación de la integración.

\section{CONFIGURACIÓN, FINALIDAD Y LEGITIMIDAD}

El título de este epígrafe es polémico, pues entiende el debate sobre la configuración y la legitimidad como un debate sobre la finalidad de la integración europea. Los académicos son prudentes cuando se refieren explícitamente a la finalidad, al objetivo último ${ }^{113}$. Sin embargo, de los trabajos sobre configuración y legitimidad de la Unión se pueden deducir con un pequeño esfuerzo bosquejos sobre su finalidad, es decir, sobre la constitución de la Unión: es propio de la naturaleza evolutiva y constructiva del pensamiento jurídico querer, cuando menos, identificar la lógica presente en la esencia de la realidad y, a través de un trabajo jurídico proponente, ayudar a su realización. Para ello, ningún ámbito de

109. Enfáticamente W. HallsteIn: Die Europäische Gemeinschaft, 1979, pp. 51 y ss.; escépticamente R. Dehosusse/J.H. WeILER: "The legal dimension", en the Dynamics of European Integration, Ed. Wallace, 1991, p. 242. En esta relación se han de inordinar los trabajos sobre la implementación $\mathrm{H}$. SIEDENTOPF/J. ZILLER: L'europe des administrations? La mise en oeuvre de la législation communautaire dans les Etats membres, 1988; J. SCHWARZE/U. BECKER/C. POLLAK: Die Implementation von Gemeinschaftsrecht, 1993.

110. M. CAPELLETI/D. GolAY: "The Judicial Branch in the Federal and Transnational Union: Its Impact on integration", en Integration Through Law, Vol. I Libro 2, 1986, pp. 261, 300, 344 , 348 y ss.

111. V. DANwITZ (nota 71); J. MASING: Die Mobilisierung des Bürgers für die Durchsetzung des Rechts, 1997; J. COPpel/A. O'NeILL: "The European Court of Justice: taking rights seriously?, LS 12 (1992), pag. 227.

112. Cfr. el desarrollo de los principios constitucionales, II 5.

113. Cfr. las contribuciones en P.M. Huber: Das Ziel der europäischen Integration, 1996; M. NeTTESHEIm/P. SChiERa: Der integrierte Staat, 1999; Ipsen (nota 20), pp. 995, 997; Hallstein: Die Europäische Gemeinschaft, p. 402; KIRCHHOF (nota 52), párrafo 2. 
la ciencia del Derecho comunitario es más adecuado que el debate sobre la configuración y la legitimidad.

La concepción afín al Derecho del Estado ve en la Unión una organización internacional de corte intergubernamental, si bien con algunas peculiaridades. Esta organización -según el núcleo esencial de esta doctrina- no está en situación de dotarse de autonomía política y jurídica, sino que permanece fundamentalmente dependiente de los EEMM, Estados-nación soberanos. Toda construcción jurídica responsable debe reflejar el enraizado político existencial de la Unión en los Estados Miembros, que detentan la responsabilidad política final ${ }^{114}$. Esta concepción -ahí reside su poder de seducción- tiene escasa necesidad de modificar las figuras dogmáticas de las que se ocupa el Derecho Público. Desde esta base, Paul Kirchhof ha caracterizado la Unión como unión de Estados ${ }^{115}$, con lo que ha logrado una formula muy influyente ${ }^{116}$. El Tratado de la Unión Europea contiene elementos que pueden confirmar esta posición ${ }^{117}$. Aunque en verdad también se puede explicar como un paso hacia la estatalización ${ }^{118}$.

Al otro lado del espectro se encuentra una concepción que orienta la integración hacia una estatalización, hacia una forma de dominio político y jurídico que realiza elementos del constitucionalismo federal. La primera gran formulación de esta visión aparece en Bundesstaat in Werden ${ }^{119}$, obra de Hallstein, primer presidente de la Comisión, que, en palabras de sus contemporáneos, marcó profundamente la "vocation" de la institución ${ }^{120}$. Ahora bien, si se consideran los polémicos derroteros del federalista europeo Federico Mancini en comparación con Paul Kirchhof, representante fundamental de la posición contraria, la sustancia de esta

114. KAUFMANN (nota 48), p. 532, con la dramática consecuencia de reconocer al Consejo como poder constituyente permanente, p. 533.

115. Nota del traductor: sobre este concepto véase la nota 65.

116. P. KIRCHHOF: "Der deutsche Staat im Prozess der europäischen Integration", en Handbuch des Staatsrechts, Ed. Isensee/Kirchhof, Vol. 7, 1992, 』 183; del mismo autor: "Das Maastricht-Urteil des Bundesverfassungsgerichts", en Der Staatenverbund der Europäischen Union, Ed. Hommelhoff/Kirchhof, 1994, p. 11; del mismo modo E. KıEIN: "Der Verfassungsstaat als Glied einer europäischen Gemeinschaft", VVDStRL 50 (1991), pp. 56, 59; A PELLET: "The Legal Bases of Community Law in International Law" en Collected Courses of the Academy of European Law, 1994, Vol. V-2, Ed. Academy of European Law; desde la ciencia política F. SCHARPF: Regieren in Europa. Effektiv und demokratisch?, 1999, pp. 19 y ss.; A. MoRAVSCSIK: "Preferences and Power in the European Community", JCMSt 31 (1993), p. 473.

117. D. CuRTIN: "The constitutional structure of the Union: A Europe of bits and pieces", $C M L$ Rev. 30 (1993), p. 17; E. DeNZA: "Two Legal Orders: Divergent or Convergent?" ICLQ 48 (1999), p. 257; A. Moravslsik/K. NiCOlaides: "Keynote Article: Federal Ideas and Constitutional Realities in the Treaty of Amsterdam", JCMSt 36 (1998), p. 13.

118. Desde una perspectiva crítica R. ScHolz: "Grundgesetz und europäische Einigung", NJW 1992, pp. 2.593, 2.594.

119. W. Hallstein: Der unvollendete Bundesstaat, 1969, pp. 39, 252, 254 y ss., incluso en su quinta edición, titulada "Die Europäische Wirtschaftsgemeinschaft" permanece la finalidad federalista inafectada; E. Grabitz: "Der Verfassungsstaat in der Gemeinschaft", $D V B l$, 1977, p. 786; F. Mancini: "Gründe für einen Gesamtstaat", KritV 1998, p. 386; de modo similar Commissariat Général du Plan: L'Union européene en quete d'institutions légitimes et efficaces (rapports Quermonne, La Documentation francaise), 1999, pp. 42 y ss. J. Shaw: «Europen Union Legal Studies in Crisis? Towards New Dynamics", OJLS 16 (1996), pp. 231, 238.

120. H. vON GROEBEN: “Walter Hallstein als Präsident der Kommission”, Integration 1993, pp. 189 y ss., 196. 
concepción no parece estar en su mejor forma ${ }^{121}$. Que no es así lo muestra Ingolf Pernice: a él se le debe agradecer una profunda reformulación de esta visión, cuyo elemento central no es el Estado, sino la Constitución $n^{122}$. Su concepción expone detalladamente uno de los nuevos desarrollos más interesantes.

Wallter Hallstein concibió la Comunidad Europea como Comunidad de Derecho y así creó un concepto central necesitado de entendimiento ${ }^{123}$. Este concepto tiene varios aspectos; uno de ellos marca esencialmente las diferencias fundamentales entre la Comunidad y los Estados Miembros. El Estado -en consonancia con la doctrina dominante- es una unidad política previa a la Constitución. El Estado como organización y la nación como comunidad de destino se dan una Constitución, por contra, la Comunidad no es nada más que una creación del Derecho $^{124}$. Este entendimiento de las relaciones entre el Estado y la Constitución está bajo crítica desde los años sesenta (Horst Ehmke, Konrad Hesse, Peter Häberle). El núcleo de esta crítica implica que el Derecho Constitucional no resulta de una realidad inmaterial "Estado", sino que la Constitución constituye el Estado ${ }^{125}$.

Ingolf Pernice aplica esta comprensión al Derecho primario abriendo así nuevas perspectivas. En primer lugar liquida la diferencia recibida de Hallstein entre Comunidad (Unión) y Estados Miembros: ambos - por lo menos desde una perspectiva jurídica- son creación del Derecho, es decir comunidades de Derecho, o mejor: comunidades constitucionales. Otro cambio fundamental de perspectiva y concepción lo implica su propuesta sobre la unidad del ordenamiento jurídico. Pernice argumenta que el -indiscutible- entretejido de los ordenamientos ha alcanzado una dimensión que responde adecuadamente al concepto de ordenamiento jurídico único ${ }^{126}$. Con ello da de baja a uno de los lugares comunes del Derecho comunitario, a saber, el supuesto de los sistemas jurídicos autónomos. Una cita ilumina el alcance de esta nueva concepción: "national administrative bodies are in an agency-situation regarding the transposition and application of community law, in fact they are part of the European executive and exercising European authority

121. MANCInI (nota 115) se remite entre otros a M.D. DubBER: "The German Jury and the Metaphysical Volk: From Romantic Idealism to Nazi Ideology", American Journal of Comparative Law 43 (1995), pp. 227, 259. Otras razones de Mancini se apoyan en el buen funcionamiento de la democracia en la India, Italia y Suráfrica.

122. I. PERNICE: "Die Dritte Gewalt im europäischen Verfassungsverbund", EuR 1996, pp. 27 y ss.; del mismo autor: "Multilevel Constitutionalism and the Treaty of Amsterdam: European ConstitutionMaking Revisite?", CMLRev. 36 (1999), pp. 703 y ss.; del mismo autor: FAZ de 7.7.1999, p. 7. La Constitución es el punto central del instituto por el dirigido Walter-Hallstein-Instituts für europäisches Verfassungsrecht an der Humboldt Universität, www.rewi.hu-berlin.de/WHI/.

123. Hallstein (nota 113), pp. 33 y ss.; G. NicOlAYSEN: "Europa als Rechtsgemeinschaft", en Handbuch Europa, Ed. Weidenfeld, 1985, p. 152.

124. U. EvERLING: "Bindung und Rahmen: Recht und Integration", en Die Identität Europas, Ed. Wedenfeld, 1985, p. 152.

125. Esta cuestión marca un cisma en el Derecho público alemán: bien sea porque se defiende el Derecho constitucional, así E. BendA/W. MAIHOFER/H.-J. VoGEL: Handbuch des Verfassungsrechts, 2." Ed., 1994, o sea para defender el Derecho del Estado, así P. KIRCHHOf/J. IsENSEE: Handbuch des Staatsrechts, Vol. IX, 1987-1997. Informativo H. SCHULZE-FIELITZ: “Grundsatzkontroversen in der deutschen Staatsrechtslehre nach 50 Jahren Grundgesetz", Die Verwaltung 1999, p. 241; J. GonZÁLEZ ENCINAR: "Derecho del Estado y Ciencia del Estado", Rev. Esp. de Derecho Constitucional 14 (1994), p. 333.

126. I. PeRnice en GG-Kommentar, Ed. Dreier, 1998, artículo 23, párrafo 20. 
(sic!)"127. Se muestra con claridad la última versión federal de la Unión. Y ahí reside el contenido propio de la construcción unión de Constituciones: la reunión de los Tratados fundacionales y las Constituciones de los Estados Miembros en una unión constitucional, que conforma la Constitución europea, lleva implícito un alto grado de construcción federal, expresión al mismo tiempo de una creciente homogeneidad en los valores del espacio europeo ${ }^{128}$. Con Ingolf Pernice la visión del Estado federal europeo ha encontrado de nuevo una voz científico-jurídica del más alto nivel dogmático.

Las anteriores versiones alternativas sobre la configuración y finalidad de la integración europea se vieron pronto desafiadas por concepciones que ven en la Comunidad una nueva forma de dominio político jurídico que sólo puede ser correctamente entendida y desarrollada al margen de aquel dualismo. En este tercer espacio del debate sobre la configuración se puede incluir toda concepción que vincula esencialmente la configuración de la integración a los fines materiales del TC(E!)E: form follows function. De la atención al espacio lingüístico alemán resultan dos grandes variantes de esta concepción, con orientaciones totalmente distintas.

De importancia descollante para la ciencia alemana, pero casi sin recepción internacional, es la doctrina de Hans Peter Ipsen, que concibe las Comunidades como asociación de integración en función de objetivos ${ }^{129}$ : son un instrumento de realización técnica de los objetivos fijados democráticamente en los Tratados. El TCEE es una Constitución planificadora para la realización del mercado común. Esta concepción se incardina en la tradición del Derecho público económico alemán ${ }^{130}$. Se puede leer como afirmadora de la integración, pero defensora de la estatalidad de los Estados Miembros frente a la concepción federal de Hallstein ${ }^{131}$. Giandomenico Majone sigue un planteamiento similar: conceptualiza la Comunidad europea desde la base de la bibliografía estadounidense sobre las Regulatory Agencies y contribuye fundamentalmente al entendimiento y desarrollo de la asociación europea ${ }^{132}$.

En este tercer ámbito la configuración alternativa la presenta Ernst Joachim Mestmäcker y su escuela. Para ellos los contenidos y fines materiales del TCEE ocupan un lugar central, sin embargo, destacan en mayor medida el contenido

127. PERNICE (nota 122), p. 724.

128. Sobre la cultura constitucional común europea también P. HäBERLE: Europäische Rechtskultur, 1994, pp. 37 y ss.

129. IPSEN (nota 19), pp. 196, 1.055.

130. En detalle U. EverLING: "Von Zweckverband zur Europäischen Union. Überlegungen zur Struktur der Europäischen Gemeinschaft", en FS Ipsen, 1977, p. 595, que encuentra elementos tanto de la calificación de la Constitución del Reich de 1870/71 que realiza Naumanns, así como de los concepto Smendianos.

131. K. ZWEIGERT: "Das große Werk Ipsens über das europäische Gemeinschaftsrecht”, EuR 1972, pp. 308,319 y ss.

132. MAJONE (nota 28). Majone trabaja sin referencias a Ipsen. Aquí se muestran los problemas de relación de la dogmática alemana: ¿cómo se puede valorar su influencia, si el concepto central de uno de sus autores más importantes no se abre camino en los trabajos de un autor que trabaja en el único instituo europeo? 
desregulador del Derecho primario y se fijan con más intensidad que IPSEN, más abierto políticamente, en la integración material. Mestmäcker sigue,en esencia, un constitucionalismo racional económico que, a través del TCE, define los límites a la intervención de la política económica nacional. En el trasfondo se esboza la visión de una sociedad burguesa preestatal y desnacionalizada cuya integración resulta esencialmente de la triada libertad contractual, competencia económica y propiedad. Mediante el aseguramiento constitucional de esta sociedad burguesa por los Tratados, la integración gana sentido, forma y legitimidad ${ }^{133}$. Con este planteamiento la discusión jurídica sobre la configuración se vincula a la teoría económica del Derecho, actualmente una de las corrientes teóricas más importantes ${ }^{134}$.

Estas tres posiciones sobre la configuración responden a tres concepciones de la legitimidad. Marcel Kaufmann muestra en su meritoria tesis doctoral ${ }^{135}$ cómo la concepción federal se apoya en el Parlamento europeo, la concepción finalista en la pericia técnica, es decir, en la Comisión ${ }^{136}$, y la unión de Estados en el Consejo y en los Parlamentos nacionales que lo respaldan. Respectivamente reaccionan de modo distinto al déficit democrático de la Unión: mientras que la concepción federalista se centra principalmente en las competencias del Parlamento europeo y en la igualdad del sistema electoral ${ }^{137}$, la concepción finalista no descubre un problema de democracia en la tarea reguladora ${ }^{138}$. Para la comprensión de la unión de Estados, el déficit democrático sólo puede nacer de una pérdida de competencias de los Parlamentos nacionales y una debilitación del peso del voto de los Gobiernos nacionales en el Consejo ${ }^{139}$.

El cuarto ámbito reúne toda concepción que comprende la Unión como una comunidad no estatal pero políticamente válida y democráticamente legítima, toda aquella concepción que resalta un alto grado de policentrismo. Opiniones en este sentido aparecen ya en los setenta ${ }^{140}$. Un primer gran intento de estructurar la

133. E.-J. MESTMÄCKER: "Der Kampf ums Recht in der offenen Gesellschaft", Rechtstheorie 1989, p. 273; del mismo autor: "Die Wiederkehr der bürgerlichen Gesellschaft und ihres Rechts", RJ10 (1991), p. 177; del mismo autor: "On the Legitimacy of European Law", RabelsZ 58 (1994), pp. 615, 633 y ss.; del mismo autor: "Zur Wirtschaftsverfassung in der Europäischen Union", en FS Willgerodt, 1994, p. 263; criticándolo K. GüNTHER: «Ohne weiteres und ganz automatisch? Zur Wiederentdeckung der Privatrechtsgesellschaft", RJ 11 (1992), p. 473; M. STOLLEIS: "Die bürgerliche Gesellschaft und ihr Recht”, RJ 11 (1992), p. 500; E.-U. Petersmann: "Constitutionalism, Constitutional Law and European Integration", Außenwirtschaft 46 (1991), p. 427.

134. Cfr. J.M. Buchanan: "The Constitution of Economic Policy", American Economic Review 77 (1986), p. 243; W. KERBER: "Interjurisdictional Competition within the European Union", Fordham International Law Journal, Vol. 23 (2000), p. 217.

135. M. KAUFMANN: Europäische Integration und Demokratieprinzip, 1997, pp. 224 y ss. Kaufmann sigue principalmente la concepción de Kirchhof.

136. En esta dirección habrían ido las concepciones de Jean Monnet, K. FEATHERsTONE: "Jean Monnet and the "Democratic Deficit" in the European Union", JCMSt. 32 (1994), p. 149.

137. Hallstein (nota 113), pp. 66 y ss.; P. HÄBERLE: "Verfassungsrechtliche Fragen im Prozeß der europäischen Einigung”, EuGRZ 1992, 429, 432; G. REss: “Über die Notwendigkeit der parlamentarischen Legitimierung der Rechtssetzung der Europäischen Gemeinschaften", en FS Geck, 1989, p. 625.

138. IPSEN (nota 19), 54/109 y sigs, pp. 1.044 y ss.; G. MAJONE: "Europe's Democratic Deficit: The Question of Standards", ELJ 4 (1998), p. 5.

139. KAUFMANN (nota 130), pp. 284 y ss.

140. EVERLING (nota 125), p. 595, principalmente en el Festschrift für Hans Peter Ipsen. 
especificidad constitucional de la Comunidad resultó por primera vez en el que ha sido durante largo tiempo el proyecto investigador más importante en la ciencia del Derecho comunitario dentro de una Universidad europea: “Integration through Law, ${ }^{141}$. En la introducción programática, los editores explican la Comunidad como una forma de dominio policéntrica y no estatal, y la conceptualizan a partir de una doble matriz: por un lado apelando al pensamiento federal, que no de Estado federal, por otro comparándolo al desarrollo estadounidense ${ }^{142}$. Esta doble matriz es significativa: muestra que el trabajo científico-jurídico necesita una idea directriz que acarree de manera útil el contenido normativo y constitucional de la modernidad, pero también un parámetro comparativo, pues la construcción de un sistema de modo comparativo muestra el núcleo de la tarea científico-jurídica. Esta introducción ofrece el estado de cosas de aquella época y las dificultades de esta comprensión, su visión federal pero no de Estado federal sólo se puede explicar con conceptos más vagos y generales.

A la luz de este planteamiento ha surgido una pléyade de estudios, aun cuando lo adecuado de la matriz federal se discute con fuerza en este ámbito ${ }^{143}$. La figura central es Joseph H. Weiler que ha dado una considerable substancia a esta concepción con sus trabajos, desde comienzo de los ochenta, sobre las relaciones entre el Derecho supranacional y la política intergubernamental, la lógica de desarrollo, la legitimidad del trabajo del Tribunal de Justicia, los valores del proceso de integración europea y las posibles estrategias de democratización ${ }^{144}$. Su programa se basa en la aceptación de que la Unión ofrece nuevas posibilidades de realización al contenido emancipatorio de la modernidad europea, pero también puede provocar tendencias destructivas si no se acometen ciertas reformas ${ }^{145}$. La posibilidades emancipatorias consisten en la permanencia de los Estados Miembros y las naciones como unidades políticas de pleno sentido, cuyas tendencias problemáticas son reprimidas por la Unión mediante principios universales. El problema democrático conduce al plano fundamental del teorema "multipler demoin" ${ }^{146}$.

141. M. CAPPELLETTI/M. SECCOMBE/J. WeILER: Integration through Law: Europe and the American Federal Experience, Vol. 1: Methods, Tools and Institutions (1985), Vol. 2: Enviroumental Protection Policy (1985), Vol. 3: Consumer Law, Common markets and Federalism i Europe and the United States (1987), Vol. 4: Legal Harmonization and the Business Enterprise (1988), Vol. 5: The Legal Integration of Energy Markets (1987).

142. CAPPELLETI/SECCOMBE/Weiler: "Integration Through Law: Europe and the American Federal Experience. A General Introduction", en (nota 137), pp. 3, 7 y ss., 12 y ss.

143. J. SHAw/A. WiEner (nota 31) lo señalan como "emotive term". Favoreciendo la perspectiva federal O. Due: "Article 5 du traité CEE. Une disposition de caractère fédéral?", en Collected Courses of the Academy of European Law, 1991-Vol. II-1 p. 15, Ed. Academy of European Law; U. EVERLING: "Zur föderalen Struktur der Europäischen Gemeinschaft", en FS Doebring, 1989, p. 179; K. LENAERTS: "Constitutionalism and the Many Faces of Federalism", AJCL 38 (1990), p. 205.

144. Los trabajos más importantes se reúnen en el volumen de Weller (nota 81), en especial en la pp. 86 y.ss., 221 y ss., 264 y ss., 324 y ss. Su significado se muestra claramente en el artículo de Paul Craig, el famoso ius publicista británico, donde se refiere a los conceptos de Weiler, CRAIG (nota 97), pp. 28 y ss., 32 y ss. También mis reflexiones se vinculan a estas posiciones, v. BoGDANDY: (nota 63).

145. J.H. WeILER: "Bread and Circus. The State of European Union", Columbia JEL 4 (1998), p. 225.

146. WeILER (nota 42), pp. 119 y ss. 
Pretende evitar el problema de la legitimidad mediante una diferenciación: el plano internacional de las conferencias intergubernamentales, el plano supranacional de la legislación por loṣ órganos centrales de la Unión y el plano infranacional de la estructura administrativa europea. Cada plano requiere un mecanismo de legitimidad, que debe desarrollar su propia lógica. Unido a ello aparece un cúmulo de innovadoras reflexiones sobre el problema de la democracia ${ }^{147}$.

\section{CONSTRUCCIÓN DE LA UNIDAD Y FRAGMENTACIÓN}

La construcción de las Comunidades como unidad de dominio y el desarrollo de su Derecho como ordenamiento jurídico unitario, fueron motivos dominantes en la construcción del acquis communautaiere ${ }^{148}$. No obstante, al comienzo de los ochenta hubo reflexiones que se ocuparon de estudiar cómo reaccionarían a la creciente homogeneidad los distintos intereses y sensibilidades de los Estados Miembros. Enseguida se vio y se reconoció la creciente necesidad de una cierta diferenciación $^{149}$. La idea de una competencia entre los sistemas nacionales -desarrollada sobre todo en el marco del programa de un mercado común orientado en torno a la competencia- lima con fuerza el dogma de la unidad ${ }^{150}$. Posteriormente, el Tratado de Maastricht cuestionó fundamentalmente el dogma de la unidad: codujo a la extendida preocupación de que la difusa estructura de la Unión entierra la unidad y el carácter supranacional de la Comunidad, es decir, su nervio vital ${ }^{151}$.

Tres líneas de investigación analizan este desafío: la primera se ocupa de la Constitución organizativa de la Unión, la segunda investiga las estrategias prácticas de diferenciación y desarrolla criterios de diferenciación dentro del Tratado de la Unión $^{152}$, y la tercera quiere presentar la fragmentación y diferenciación no como

147. R. DeHousse: "Constitutional Reform in the European Community. Are there Alternatives to the Majoritarian Avenue?", West European Politics 18 (1995), p. 118; D. CurTin: "Betwixt and between: Democracy and Transparency in the Governance of the European Union", en WINTER (nota 58), p. 95; J.H. WeILER: "The European Union Belongs to its Citizens: Three Immodest Proposals", ELRev. 22 (1997), p. 150; C. Joerges/J. NeYER: "From Intergovernmental Bargaining to Deliberative Political Processes: The Constitutionalisation of Comitology", ELJ 3 (1997), p. 273.

148. P. Dagtolou: "Die Rechtsnatur der Europäischen Gemeinschaft", en Kommision (nota 51), pp. 37,45 .

149. Cfr. C.-D EhlermanN: "How flexible is Community Law?", Michigan Law Review 82 (1984), p. 1.274; del mismo autor: "Increased differentiation or stronger uniformity", en Reforming the Treaty on European Union, Ed. Winter/Curtin/Kellermann/de Witte, 1996, p. 27; E. GraBITZ: Abgestufte Integration. Eine Alternative zum berkömmlichen Integrationskonzept?, 1984.

150. N. REICH: "Competition between legal orders -A new paradigm of EC law?", CMLRev. 29 (1992), p. 861; KERBER (nota 129); S. WoOLCOCK: The Single European Market: Centralization or Competition Among National Rules, 1994. La importancia del postulado de unidad se muestra en la vehemente crítica de Pierre PEscATORE al comentar el Acta Única: "Die "Einheitliche Europäische Akte" -Eine ernste Gefahr für den Gemeinsamen Markt», EuR, 1986, p. 153.

151. U. EverLING: "Reflections on the Structure of the European Union", CMLRev. 29 (1992), p. 1.052; CuRTIN (nota 112), p. 67.

152. TuYtschaever: Differentiation in European Union Law, 1999; I. DeKKer/Wessel: "Proliferation of Legal Systems within International Organizations: The European Union and the Concept of Flexibility", en Proliferation of International Organizations, Ed. Schermers/Blokker, 2000. 
un "pecado", sino como un principio constitucional que concreta la configuración "sui-generis" de la Unión ${ }^{153}$. Estos debates jurídicos se incardinan en el contexto de visiones políticas cuyos lemas son "Europe à la carte", "variable geomètry" o simplemente "variable speed" $" 154$.

A continuación describiremos únicamente la primera línea de investigación, que ha conducido al debate más diferenciado. Sus motivos de fondo resultan de las vagas fórmulas de compromiso de la nueva Constitución organizativa, fundamento del Tratado de Maastricht: metáforas que no encuentran anclaje ni en la teoría del Estado ni en la teoría de la organización (templo, columnas, pilares). Se necesitará un buen trecho hasta que la ciencia jurídica cierre estos retos de manera constructiva. Así, en torno a la Constitución organizativa se desarrolla un debate sobre la configuración, con distintas y controvertidas posiciones, que, pese a algunas conexiones con los debates expuestos anteriormente, goza de autonomía.

Actualmente existen fundamentalmente cuatro concepciones distintas sobre la Unión como organización y su relación con las Comunidades. Según la concepción formulada esencialmente por Christian Koenig y Matthias Pechstein la Unión no constituye una organización, sino que únicamente designa una conferencia de los representantes de los Estados Miembros ${ }^{155}$; por tanto, sólo las Comunidades existentes forman organizaciones autónomas. Una segunda concepción, la opinión mayoritaria, parte del reconocimiento de cuatro organizaciones, si bien a la Unión le falta personalidad jurídica ${ }^{156}$. Una tercera opinión, desarrollada principalmente por Oliver Dörr, constata igualmente la existencia de cuatro organizaciones, aunque, en gradación interna ${ }^{157}$. La cuarta concepción considera, por contra, una fusión organizativa de las Comunidades en la Unión, de modo que organizativamente se parte de una única organización ${ }^{158}$.

La autonomía de este debate frente a las "grandes descripciones" funda su significativo contenido técnico jurídico: conceptos como asociación, órgano, organización, personalidad jurídica o unidad del ordenamiento jurídico ocupan un lugar central. Las específicas habilidades de la ciencia jurídica-coherencia, profunda precisión conceptual- se muestran mejor en este objeto que en las "grandes descripciones". Sin embargo, las cuatro versiones sobre la Constitución organizativa

153. Sobre ello ver el epígrafe II 5.

154. A. STUBB: "A Categorization of Differentiated Integration", JCMSt 34 (1996), p. 283.

155. M. PeChTSTein/C. KoeniG: Die Europäische Union, $2 .{ }^{a}$ Ed., 1998, párrafo 55 y ss.; C. Koenig: "Die Europäische Union als bloßer materiellrechtlicher Verbundrahmen", EuR Beiheft 2/1998, p. 139; A.D. PliakOs: “La nature juridique de l'Union européenne", 22 RTDE (1993), pp. 187, 213.

156. Cfr. M. Hilf/E. PACHE, en GRabitz/Hilf, EU-/EGV-Kommentar, actualización 1995, artículo A, párrafo 25 y ss.

157. O. DöRR: "Zur Rechtsnatur der Europäischen Union", EuR 1995, p. 334; B. DE WITTE: “The Pillar Structure and the Nature of the European Union: Greek Temple or French Gothic Cathedral?", en The European Union after Amsterdam, Ed. Heukels/Blokker/Brus, 1998, pp. 51, 55.

158. A. v. BOGDANDY/M. NetTESHEIM: "Die Europäische Union: Ein einheitlicher Verband mit einheitlicher Rechtsordnung", EuR 1996, p. 3; A. v. BOGDANDY: "Die Europäische Union als einheitlicher Verband", EuR Beiheft 2/1998, p. 165; CURTIN/DekKer (nota 104), p. 131; M. ZuleEg: "Die Organisationsstruktur der Europäischen Union", EuR Beiheft 2/1998, p. 151. 
se apoyan implícitamente en concepciones teóricas sobre la integración y en premisas políticas; una argumentación de deducción puramente dogmática es imposible si se atiende a la falta de concreción y a las antinomias del texto del Tratado. La distinción entre Unión y Comunidades se basa en preocupaciones opuestas. Tal distinción puede tener como intención proteger la especifica unidad de la Comunidad y su Derecho ${ }^{159}$ frente a la amenaza del ámbito intergubernamental, si bien se puede apoyar en un motivo integrador distinto, no permitir que la Unión se refuerce e impedir así que el acercamiento político y jurídico de los Estados Miembros gane peso. La fragmentación es de este modo instrumento del dominio de los Estados Miembros -divide et impera. La tesis de la unidad, por el contrario, ve amenazados en la fragmentación organizativa importantes postulados de la modernidad europea ${ }^{150}$. Ven la unidad organizativa como condición de una diferenciación funcional y normativa convincente, adecuada para cumplir las funciones inevitables de una Unión en expansión.

\section{PRincipios CONSTITUCiOnales}

Si una tarea fundamental de la dogmática constitucional consiste en destacar principios, entonces la dogmática constitucional europea tiene ante sí todavía un trabajo ingente ${ }^{161}$. Aquí se muestra una clara diferencia entre el Derecho constitucional europeo y el nacional. Los buenos manuales de Derecho constitucional nacional comienzan normalmente con la exposición de los principios que estructuran el conjunto del ordenamiento jurídico ${ }^{162}$. La mayoría de las veces se busca en vano algo similar en los trabajos de Derecho comunitario ${ }^{163}$. Ni si quiera se tiene claro qué materias jurídicas pertenecen al Derecho constitucional europeo. Si se observa el conjunto del articulado de los Tratados es evidente que no todo se puede tratar con pleno sentido como Derecho constitucional, mientras que mucho derecho no escrito sí164 (primacía, efecto directo, derechos fundamentales).

159. Sobre la unidad del Derecho comunitario tras Amsterdam S. KADELBACH: "Einheit der Rechtsordnung als Verfassungsprinzip der Europäischen Union", EuR Beiheft 2/1998, p. 51; J. SCHWARzE/P-C. MülleR-GrafF: "Europäische Rechtseinheit durch einheitliche Rechtsdurchsetzung”, EuR Beiheft 1/1998.

160. Para la diferenciación entre la construcción de la unidad organizativa y la estatalización A. v BogDANDY: "The legal Case for Unity" CMLRev. 36 (1999), p. 887.

161. J.H. WEILER: «European Neo-constitutionalism: in Search of Foundations for the European Constitutional Order", Political Studies 1996, 517.

162. Cfr. K. HeSSE (nota 94), $\$ 4$ y ss.; C. TuRPIN: British Government and the Constitution, 2." Ed., 1990,19 y ss.

163. Sí los emplea R. BreBer/B. KAHL-Wolf/L. Muller: "Cours général de droit communautaire", en Collected Courses of the Academy of European Law, 1992-Vol. III-1, p. 49, Ed. Academy of European Law.

164. Sobre los intentos para formar a partir de los Tratados un documento coherente y "similar a las Constituciones" C. SCHMID: "Konsolidierung und Vereinfachung des europäischen Primärrechts", Eur Beiheft 2/1998, p. 17; Parlement européen, Direction Générale des Etudes: "Quelle charte constitutionnelle pour l'Union européenne?, Série politque, POLI $105 \mathrm{Fr}$, 05-1999; M. HeINTZEN: "Hierarchisierungsprozesse innerhalb des Primärrechts der Europäischen Gemeinschaft", EuR 1994, p. 35. 
Los principios constitucionales no sirven únicamente para la estructuración del material jurídico. La elaboración dogmático-jurídica de los principios constitucionales se puede comprender como una autoafirmación de la sociedad sobre sus fundamentos normativos. Un debate concreto trata este punto: algunos teóricos del derecho encuentran en el Derecho constitucional en formación una solidificación y concreción del consenso valorativo europeo ${ }^{165}$, y otros, incluso, una manifestación de los europeos como nación ${ }^{166}$. Otros dudan sobre un desarrollo en este sentido $^{167}$. Sin duda, no se discute que los objetivos que la Unión ha de satisfacer -el aseguramiento de la paz y el bienestar en el marco de una estrecha asociación institucional europea ${ }^{168}$ - gozan, pese al escepticismo en los detalles, de una amplia aceptación y coincidencia en un grupo de posiciones fundamentales. Si bien, este consenso sobre los contenidos está menos consolidado en las distintas teorías que en los Estados Miembros ${ }^{169}$. De hecho, de una última teoría se deduce que la Unión se puede apoyar en menor medida en un consenso material, para dar más importancia a los procedimientos ${ }^{170}$.

La discusión sobre el contenido de los principios constitucionales europeos es polifónica y plural. A continuación se expondrá en cuatro grupos. El primero se ocupa de la adaptación en el sistema de la Unión de los principios constitucionales conocidos en los sistemas nacionales. El segundo grupo pretende elaborar principios constitucionales propios de esta novedosa comunidad. El tercer grupo lo forman los estudios que toman al ciudadano europeo como punto de partida del Derecho de la Unión. El último se centra en la constitución económica de la Comunidad.

En desarrollada discusión se encuentran algunos principios conocidos en las Constituciones estatales, en especial el principio democrático y el principio de Estado de Derecho. El principio Estado de Derecho se pude considerar como el de más larga tradición ${ }^{171}$, el cual es transformado para la Unión, por Manfred Zuleeg, como principio de juridicidad ${ }^{172}$; su validez fundamental está fuera de duda ${ }^{173}$. Sin embargo, existen controversias sobre las concretas instituciones que forman este principio. De gran importancia para el entendimiento fundamental de la Unión son las

165. H. STEINBERGER: "Aspekte der Rechtsprechung des Bundesverfassungsgerichts zum Verhältnis zwischen Europäischem Gemeinschaftsrecht und deutschem Recht", en FS Doebring, 1989, pp. 951, 968. p. 347.

166. Así K. BaHLMANN: "Abschied vom Gerichtshof der Europäischen Gemeinschaften", EuR 1988,

167. Escépticamente J. BASEDOw: "Zielkonflikte und Zielhierarchien im Vertrag über die Europäische Gemeinschaft", en FS Everling, Vol. 1, 1995, pp. 49, 57; SHAw (nota 114), pp. 240 y ss.

168. P.-C MüLLER-GRAFF: "Einheit und Kohärenz der Vertragsziele von EG und EU", EuR Beiheft 2/1998, pp. 67 y ss.

169. U. EverLING: "Bindung und Rahmen: Recht und Integration", en Die Identität Europas, Ed. W. Weidenfeld, 1985, pp. 152 (152, 162 y ss.); del mismo autor: "Richterliche Rechtsfortbildung in den Europäischen Gemeinschaften", JZ 2000, pp. 16 y ss.; WeILER (nota 78), pp. 108 y ss.

170. v. Bogdandy (nota 66).

171. Su validez para las Comunidades es un aspecto del concepto Comunidad de Derecho, acunado por Hallstein.

172. M. ZuLEEG: "Die Europäische Gemeinschaft als Rechtsgemeinschaft", NJW 1994, p. 595.

173. Programáticamente Karser (nota 37), pp. 32 y sigs; sobre el estado de la cuestión T.C. HARTLEY: The Foundation of European Community Law, 4.a Ed., 1998, pp. 130 y ss. 
posiciones enfrentadas sobre los derechos fundamentales. Se ha de recordar la discusión sobre su aplicación a las medidas estatales ${ }^{174}$ o la pregunta sobre el estándar de aplicación ${ }^{175}$. La comparación con el sistema constitucional americano muestra que la jurisprudencia de un tribunal central puede desarrollar enormes fuerzas centrípetas $^{176}$.

Muy polémica es la discusión sobre el principio democrático: su aplicabilidad en el plano europeo es discutida ${ }^{177}$. En este estadio la discusión se une al debate sobre la legitimidad, si bien se amplía, pues al reconocerse la democracia como principio constitucional se la desciende del cielo de lo político y se la prepara para su aplicación en controversias jurídicas. Para el resto de los principios existen a lo sumo bocetos ${ }^{178}$, situación que causa un vacío dogmático cuyo colmado se ha convertido en una urgente necesidad jurídica, en atención a los artículos 6 y 7 del TUE.

El segundo grupo se ocupa de los específicos principios constitucionales de la Unión. Si se trata de una Unión sui generis, es decir, de una nueva forma de dominio político, entonces se ha de esperar que esa especialidad tome forma en principios constitucionales originales. Aquí queda lo fundamental por hacer. El "Candidato natural", el concepto de supranacionalidad, hasta ahora no ha tomado cuerpo de principio jurídico ${ }^{179}$. Por el contrario, se ha invertido mucho trabajo en la subsidiariedad ${ }^{180}$, respecto a la cual la ciencia jurídica alemana ha dado prueba de su sorprendente capacidad de producción. Otros dudan de que la especificidad pueda iniciarse desde la subsidiariedad, pues consideran que se trata exclusivamente de una regla sobre el ejercicio competencial en relación con los Estados Miembros; en su sustancia es una cláusula típica de una Constitución federal.

174. A favor R. Gosalbo Bono: "Reflexiones en torna al futuro de la protección de los derechos humanos en el marco del Derecho comunitario y del derecho de la Unión: insuficiencias y soluciones", Revista de Derecho Comunitario Europeo 1 (1997), p. 29; en contra G. BAUMGARTNER: EU-Mitgliedschaft und Grundrecbtsschutz, 1997, pp. 189 y ss., 204.

175. WeILER (nota 79), pp. 108 y ss. Sobre la convergencia y divergencia de las Constituciones nacionales J. GÜNTER: Berufsfreibeit und Eigentum in der Europäischen Union, 1998, pp. 50 y ss., 223 y ss., 249 y ss., 251; así como las contribuciones en P.C. MülLER-Graff/E. RiEdel: Gemeinsames Verfassungsrecht in der Europäischen Union, 1998.

176. CAPpelletTI/GOlaY (nota 107), pp. 197 y ss.

177. Cfr. KAISER (nota 37) "No es la tarea de nuestro tiempo establecer una democracia parlamentaria en las Comunidades". Sobre su validez M. ZuLEEG: "Der Verfassungsgrundsatz der Demokratie und die Europäischen Gemeinschaften", Der Staat 17 (1978), p. 27; en contra A. RADELZHOFER: "Zum behaupteten Demokratiedefizit der Europäischen Gemeinschaft", en Hommelhoff/Kirchhof (nota 111), p. 39.

178. Cfr. J.A. FroweIN: "Die Herausbildung europäischer Verfassungsprinzipien", en FS Maibofer, 1988, p. 149; I. PERNICE (nota 117), pp. 733 y ss.

179. Para su desarrollo M. ZuLEEG: "Wandlungen im Begriff der Supranationalität", Integration 3 (1988), pp. 3 y ss.

180. Esto responde a su ímpetu polítco, cfr. Jacques Delors' Rede im Collège d'Europe, 17 de Octubre 1989, citado de J. Trachtman: “L'Etat, c'est nous. Sovereignty, Economic Integration and Subsidiarity", HJIL 33 (1992), pp. 459, 469; en el mismo sentido Sir Leon BRITTAN: "Subsidiarity in the Constitution of the European Community", en Collected Courses of the Academy of European Law, 1992Vol. III-1, p. 19, Ed. Academy of European Law, 1994. Sobre el debate cfr. H. LeCHELER: Das Subsidiaritätsprinzip. Strukturprinzip einer europäischen Union, 1993; C. CALLIES: Subsidiaritäts-und Solidaritätsprinzip in der Europäischen Union, 2." Ed., 1999. 
La investigación sobre otros principios específicos es exigua y fragmentaria, incluso para instituciones tan centrales como la efectividad y la unidad de eficacia $^{181}$. El debate más importante referido a los principios constitucionales específicos -la mayoría en atención al concepto de la Unión de Joseph Weiler- pretende amoldar en principios el carácter plural, no jerárquico, dialéctico y postnacional de este orden constitucional ${ }^{182}$. En especial, las investigaciones de Josephine Shaw incluyen nuevas dimensiones. Intenta concebir principialmente fenómenos como "desintegración", "flexibilidad", hasta ahora vistos como amenazas del proceso de integración, de modo que al igual que la integración y la unidad formen parte de la Constitución europea. Al mismo tiempo, este intento debe deshacer el vinculo entre Derecho supranacional e integración, visto como un lazo axiomático por generaciones de comunitaristas. Mantiene la opinión de que para realizar una descripción dogmática del derecho positivo que responda más justamente que el planteamiento dominante a la actual tendencia del desarrollo del Derecho, y al mismo tiempo ordenar el Derecho de la Unión en un marco constitucional equilibrado, se ha de dar cuenta de la diversidad de los miembros de la Unión ${ }^{183}$.

El tercer grupo lo constituyen aquellas contribuciones que quieren recuperar para el Derecho supranacional el proceso que más ha contribuido a la reforma del Derecho público alemán desde 1949: la reconstrucción del ordenamiento jurídico con el ciudadano como punto de partida ${ }^{184}$. En última instancia se trata de desligar a este cuerpo jurídico de su función primaria como instrumento político para inducir el cambio social. Ciertos elementos se encuentran en un escrito visionario de Eberhard Grabitz del año $1970^{185}$, si bien la inclusión del instituto de la ciudadanía europea mediante el Tratado de Maastricht ha conducido a un extenso debate para concebir la condición del individuo más allá de su condición de "ciudadano del mercado" ${ }^{186}$. La condición y la importancia de la ciudadanía europea en los Tratados es muy discutida. Mientras que algunos ven en ella "little more than a cynical exercise of public relations" ${ }^{187}$, otros localizan el inicio de un nuevo entendimiento $^{188}$. La correspondiente renovación de la red de conceptos jurídicos

181. F. SNYDER: "The Effectiveness of European Community Law", Modern Law Review 56 (1993), p. 19; M. NetTesheIm: "Der Grundsatz der einheitlichen Wirksamkeit des Gemeinschaftsrechts", en $G S$ Grabitz 1995, p. 447.

182. Cfr. los autores citados en la nota 97.

183. SHaw (nota 114), pag. 240 y ss.; del mismo autor: "Citizenship of the Union", en Collected Courses of the Academy of European Law, 1995-Vol. VI-1, p. 237, Ed. Academy of European Law, 1998; del mismo autor: "Postnational constitutionalism in the European Union", JEPP 1999, p. 579.

184. SCHMIDT-ABMANN (nota 11), pp. 56 y ss.

185. E. GRABITZ: Europäische Bürgerschaft zwischen Marktbürgerschaft und Staatsbürgerschaft, 1970; sobre ello A. RANDELZHOFER: "Marktbürgerschaft-Unionsbürgerschaft-Staatsbürgerschaft", en $G S$ Grabitz, 1995, p: 581.

186. Aquí, como a menudo, la ciencia no ha inspirado o motivado el desarrollo político, sino que con esfuerzos le ha ido a la zaga.

187. J.H. WeILER: "European Citizenship and Human Rights", en Reforming the Treaty on European Union, Ed. Winter/Curtin/Kellermann/de Witte, 1996, pp. 57, 65.

188. G. FRANKENBERG: "L'avenir de la citoyenneté en Europe après Maastricht", Cabiers Dakarois 1995, p. 10; U.K. Preuss: "The Relevance of the Concept of Citizenship for the Political and Constitutional Development of the EU", en Europea Citizenship, Multiculturalism, and the State, Ed. Preuss/Requejo, 
es una misión obligada -así lo muestran los primeros trabajos ${ }^{189}$. Las investigaciones realizadas hasta ahora hacen patente que en Derecho de la Unión debe haber cambios fundamentales, si realmente se pretende pasar de un Derecho de planeamiento político a un Derecho que toma como punto de partida al individuo.

Una diferencia fundamental entre la dogmática constitucional nacional y la europea, radica en que ésta última no es monopolizada por ius publicistas. En el Derecho comunitario alemán los privatistas (por ejemplo, Walter Hallstein, Bodo Börner, Ernst-Joachim Mestmäcker, Ernst Steindorff) fueron y son tan protagonistas como los académicos del Derecho público (por ejemplo, Hans Peter Ipsen, Josef H. Kaiser, Eberhard Grabitz, Manfred Zuleeg) ${ }^{190}$. Como mostró la construcción del TCE, las preguntas materiales sobre Derecho económico no tienen un peso menor que los problemas de organización o de derechos humanos. Los diversos debates sobre los aspectos materiales del TC(E)E se podrían entender como una explicación de los principios de la Constitución económica europea ${ }^{191}$. En ellos no se concibió el TCEE exclusivamente como bastión frente a las transformaciones socialistas. Junto al establecimiento de los espacios económicos propios de la economía de mercado, el Tratado produce efectos liberalizadores y desregulativos. Se produjeron fuertes debates cuando las Comunidades obligaron a liberalizar servicios que clásicamente habían estado bajo titularidad estatal ${ }^{192}$. Fritz Scharpf articuló una extendida desazón al lamentar la asimetría de los Tratados, favorecedores de la construcción del mercado y penalizadores de la regulación del mercado ${ }^{193}$. Mientras que un sector de la doctrina teme la socavación del Estado social, otro muestra su preocupación por el enriquecimiento del TCE mediante elementos sociales e intervencionistas, incorporados por el Tratado de Maastricht y el Tratado de Amsterdam. Desde este punto de vista, la Unión esta bajo la amenaza de una pérdida de legitimidad, cuando la orientación de los Tratados en favor de la competitividad se ve debilitada por momentos sociales e intervencionistas ${ }^{194}$. En

1988, p. 11; N. REICH: "A European Constitution for Citizens: Reflections on the Rethinking of Union and Community Law", ELJ 1997, p. 131; J. SHAw: "The Interpretation of European Union Citizenship", Modern Law Review 1998, p. 293.

189. S. KADELBACH: "Staatsbürgerschaft-Unionsbürgerschafft-Weltbürgerschaft", en Europäische Demokratie, Ed. Drexl/Dreuzer/Scheuing, 1999, pp. 89 y ss.; N. ReICH: Bürgerrecht in der Europäischen Union, 1999.

190. Me parece que esta es una diferencia esencial con otros Estados Miembros, como por ejemplo Italia, donde el Derecho comunitario es casi exclusivamente cosa de los internacionalistas.

191. M. ZuLEEG: "Die Wirtschaftsverfassung der Europäischen Gemeinschaften", en Wirtschafts- und gesellschaftspolitische Ordnungsprobleme der Europäischen Gemeinschaften, 1978, p. 73; C. JOERGES: "Wirtschaftsrecht, Nationalstaat und der Vertrag von Maastricht", Leviatban 21 (1993), p. 499; una visión general por W. MussleR: Die Wirtschaftsverfassung der Europäischen Gemeinschaften im Wandel, 1998, pp. 21 y ss.

192. S. SCHмIDT: "Commission Activism. Subsuming Telecommunications and Electricity. under the European Competition Law", Journal of European Public Policy 5 (1998), p. 169; A. PAPpALARDO: "Der Europäische Gerichtshof auf der Suche nach einem Kriterium für die Anwendung der Wettbewerbsregeln auf staatliche Maßnahmen", en FS von der Groeben, 1987, p. 303; G. BAuER: Wettbewerbsbeschränkungen durch Staaten? Die Verantwortung der Mitgliedstaaten der Europäischen Gemeinschaft für den Wettbewerb im Gemeinsamen Markt, 1990.

193. F. SCHARPF: Regieren in Europa. Effektiv und demokratisch?, 1999, p. 52 y ss.; igualmente E.-W BÖCKENFÖRDE: Welchen Weg geht Europa?, pp. 21 y ss.

194. Mestmäcker (nota 128) RabelsZ 1994, pp. 634 ss. 
lenguaje jurídico este debate toma cuerpo en la configuración de las competencias industriales, la frontera de las competencias reguladoras de la Unión o la pregunta sobre si en caso de conflicto el principio de competencia económica prima sobre otros principios y objetivos ${ }^{195}$.

Ahora, este debate se ve completado y precisado por otro debate que abre una nueva dimensión: la posición de la Unión en el mundo. Al margen de una plétora de problemas ${ }^{196}$, hasta ahora sólo ha existido una controversia de carácter jurídico: las relaciones del Derecho de la Unión con el Derecho de la OMC. Las relaciones entre la integración europea y el GATT han sido difíciles desde el principio $^{197}$; estas dificultades se han agravado en un debate conflictivo. Éste se puede entender como un desplazamiento del debate interno sobre la Constitución económica, en cuanto que algunos ven en el Derecho de la OMC la garantía global de la economía de libre mercado, que se pone en cuestión a nivel europeo mediante la incorporación de elementos sociales e intervencionistas en el TCE ${ }^{198}$. En concreto se trata de la aplicación directa del Derecho de la OMC y las decisiones del Tribunal arbitral, e implícitamente sobre la naturaleza de la OMC como Constitución económica internacional. La OMC podría presentar en el futuro el mayor reto de la Unión: si se desarrolla en un marco eficiente para la solución de problemas, se ha de esperar que la discusión presentada en este trabajo para la Unión se repita para la OMC.

\section{PERSPECTIVAS DE DESARROLLO: HACIA LA EUROPEIZACIÓN DEL DERECHO COMUNITARIO}

En atención a la fuerza estabilizadora de las teorías, es probable que las que han sido expuestas dominen la discusión en el futuro próximo. La adhesión general la ha de esperar aquella teoría que mejor satisfaga las expectativas del "consumidor. Esta teoría debe exponer y explicar con claridad las estructuras del derecho positivo con una mirada orientada a su aplicación, debe identificar los mecanismos de la dinámica inmanente del Derecho de la Unión, pero también -y aquí reside la singularidad de la ciencia- debe desarrollar parámetros para una crítica

195. A favor J. BASEDOw: "Zielkonflikte und Zielhierarchien im Vertrag über die Europäische Gemeinschaft", en FS Everling, 1995, p. 49; MESTMÄCKER: “Bedeutung der Wettbewerbsregeln in der Wirtschaftsverfassung der EG (Art. 3 lit. g)", en EG-Wettbewerbsrecht, Ed. Immenga/Mestmäcker, 1997, Introducción, párrafo 36 y ss.; en contra P. Pescatore: "Les objectifs de Communauté européene comme principes d'interprétation", en Miscellanea .J. Ganshof van der Meersch II, 1972, p. 325; H. vON DER GROEBEN: "Probleme einer europäischen Wirtschaftsordnung", en FS Börner, 1992, pp. 99,116 y ss.

196. ¿Poder civil o poder militar? ¿Ingreso de Turquía? ¿Poder hegemónico frente a Africa? ¿Complementariedad o concurrencia frente a Estados Unidos?

197. H. STEINBERGER: GATT und regionale Wirtschaftszusammenschlüsse, 1963, pp. 23 y ss.

198. A fondo y en numerosos escritos E.-U PETERSMANN, cfr. "Proposals for protecting the interests of EU citizens rather than the interests of EU politicians", en WINTER (nota 183), pp. 265 y ss.; y del mismo autor: Constitutional Functions and Constitutional Problems of International Economic Law, 1991. La perspectiva opuesta carece de un proyecto general; alguna aplicación por C.-D EHLERMANN: "Die innergemeinschaftliche Anwendung der Regeln des GATT in der Praxis der EG", en GATT und die Europäische Gemeinschaft, Ed. Hilf/Petersmann, 1986, p. 203. 
sistemática $^{199}$. Sólo el trabajo de Hans Peter IPSEN -en mi opinión- se acerca a estos requisitos ${ }^{200}$. Probablemente, en atención a la complejidad, fragmentación e inmenso volumen del derecho positivo, esta tarea no es realizable por un único autor ${ }^{201}$.

De gran importancia para el desarrollo del Derecho comunitario es saber si se puede esperar una europeización de la ciencia del Derecho comunitario, de corte nacional, y qué forma podría tomar esta europeización. ¿Es tal europeización deseable? En tanto que la ciencia jurídica es en primer lugar una ciencia práctica, que trabaja sobre una central infraestructura social, la europeización, desde el punto de vista de la eficiencia, debería ser un desiderátum. Se ha de suponer que la europeización del Derecho comunitario se apoyara en primer lugar en la producción jurídica. En gran medida dependerá de la praxis del TJ y, sobre todo, de los Abogados Generales ${ }^{202}$. Si decidieran ubicarse convincente y comprensiblemente en un discurso jurídico europeo, se habría ganado mucho en favor de un discurso europeo en la cuestión central de la integración -ide la integración por el Derecho! En especial los Abogados Generales han aprovechado insuficientemente su original posición en el sistema jurídico europeo.

Pero, ¿qué significa europeización? Destacan dos modelos distintos. Uno es el modelo del mercado (interior). En este sentido, la europeización de la ciencia jurídica significa la creación de un mercado europeo de "productores" y "productos" jurídicos, de modo que la europeización, esencialmente, sería una repetición a nivel europeo de la actual situación nacional ${ }^{203}$. Dentro de las ciencias sociales, la economía parece haber tomado este camino. El modelo alternativo consiste en una europeización de los comunitaristas nacionales a la par de la europeización de la opinión pública nacional. No se ha de esperar una simple sustitución, sino complejos y fértiles procesos recíprocos, interpenetraciones, un espacio público europeo para determinadas materias así como la construcción de un espacio público común gracias a ciertos escándalos. El último modelo parece más probable y deseable. Sin embargo, requiere mecanismos específicos de vinculación al contexto y metaestructuras que permitan acomodar los debates en distintos espacios científicos, traducirlos y hacerlos útiles.

La lengua de esta metaestructura será el inglés, y los tẹ́rminos jurídicos ingleses transportarán instituciones jurídicas inglesas ${ }^{204}$. La dogmática alemana, italiana,

199. Para las funciones del ius publicista en la construcción de sistemas SCHMIDT-AßMANN (nota 11), pp. 2 y ss.

200. El trabajo de Joseph Weiler podría ser tenido en cuenta, pero le falta casi en su totalidad el derecho material económico y con él, el núcleo del Derecho comunitario.

201. También SCHMIDT-AßMANN ve el sistema esencialmente como proceso -incluso en el más limitado objeto del Derecho Administrativo alemán: “Entendido como idea ordenadora, la parte general del Derecho Administrativo no aparece tanto como canon de reglas e institutos, sino como lugar y tarea de reflexiones prospectivas y de construcción sistemática", (nota 11), p. 2.

202. Acertadamente crítico v. Danwitz (nota 68), pp. 150 y ss.; A. TEICHMANN: "Ein Europäisches Zivilgesetzbuch", en Europa als Rechtsgemeinschaft, Ed. Dörr/Dreher, 1997, pp. 17, 28.

203. Así la concepción de T. MÖLlERs: Die Rolle des Rechts im Rabmen der europäischen Integration, 1999, pp. 81 y ss.

204. En contra A. FLESSNER: "Rechtsvereinheitlichung durch Rechtswissenschaft und Juristenausbildung", RabelsZ 56 (1992), pp. 243, 257. 
española y francesa, si quieren participar en esta europeización del Derecho comunitario, se enfrentan con el dominio del inglés ante un dilema similar al que padecieron la moneda francesa, italiana y belga frente a la política monetaria europea. La coparticipación se rige por la regla del sistema más fuerte. En cuanto al dinero, el precio a pagar fue el concepto alemán de política monetaria, en la discusión jurídica el precio a pagar es la utilización del inglés, la categorías jurídicas anglosajonas y probablemente su cultura argumentativa. Esto no solamente habría de verse como una carga. La sencillez del mundo conceptual anglosajón y la transparencia de su argumentación influirán en la construcción continental del Derecho público, sirviendo a su transparencia, a la precisión de sus presupuestos e incluso -a largo plazo- modificarán el hermetismo de las culturas argumentativas nacionales. La singularidad de la ciencia jurídica continental, en atención a su alto nivel dogmático - piensese sólo en la teoría de las fuentes del derecho- no se verá amenazada por una apertura de ese tipo.

En pequeña medida hay foros e instituciones para la europeización del Derecho comunitario. De especial importancia -como muestran las notas a pie de página de este trabajo- es la Common Market Law Review, producto comunitario británico-holandés. Poco a poco encuentra el Instituto Europeo de Florencia, de dominio angloamericano ${ }^{205}$, su lugar en el proceso de europeización del Derecho comunitario, sobre todo con la Academy of European Law, cuyos Collected Courses merecen gran atención, pero también una rápida publicación y un precio aceptable $^{206}$. Se ha de mencionar también el European Law Journal editado por el Instituto, aunque en verdad, en él no se encuentra lo que se reconoce como núcleo de la ciencia jurídica continental: la construcción dogmática ${ }^{207}$. En general, es escasa la influencia del Instituto en los debates comunitarios nacionales.

Hay diferentes reflexiones para desarrollar una mayor europeización. Christoph Schmid propone, tomando como modelo el American Law Institut, el establecimiento de un European Law Institute, en el que significativos académicos y prácticos emitirían restatements sobre el derecho en vigor. Estos restatements, a diferencia de la producción florentina, en virtud del prestigio nacional de sus autores no podría ser pasado por alto ${ }^{208}$. Los Estados. Miembros y la Unión podrían decidir la sistemática y consecuente divulgación a nivel europeo de los trabajos de calidad procedentes de distintos ámbitos científicos.

La propuesta implica que la europeización del Derecho comunitario es una tarea pública. ¿Es realmente así? Se pueden establecer alternativas a una europeización

205. Durante mi estancia en el Instituto (1995-1996), en las distintas reuniones, la porción angloamericana de las lecturas de trabajo no bajaba del $50 \%$ y normalmente lo superaba. Esta elección a menudo tenía buenos motivos, lo que muestra, qué dificultades tiene la doctrina continental para realizar trabajos que se incluyan en discusiones transnacionales.

206. Sobre la europeización de la formación jurídica como condición para la europeización de los sistemas jurídicos nacionales H. KÖTZ: "Europäische Juristenausbildung", ZeuP 1993, p. 268; H.G.: SCHERMERS: "Legal Education in Europe", CMLRev. 30 (1993), p. 9; así como los trabajos en B. DE WITTE/C.

FORDER: The Common Law of Europe and the future of Legal Education, 1992.

207. Véase el subtítulo programático: Review of European Law in Context.

208. SCHMID (nota 160), pp. 34 y ss. 
espontánea y basada en el mercado. Pero sólo una europeización apoyada desde el poder público puede satisfacer los principios desde los que se fundó la integración: ausencia de hegemonía y respeto de la pluralidad ${ }^{209}$. Sin considerables esfuerzos de los Estados Miembros, el círculo jurídico anglosajón ejercerá a medio plazo una hegemonía sobre la Unión y el Derecho comunitario similar a la del Marco alemán en 1999. 